ANA LILIAN BISPO DOS SANTOS

ASSOCIAÇÃO ENTRE FATORES DE RISCO EOCORRÊNCIA DE DOENÇAS CRÔNICAS COM INSEGURANÇA ALIMENTAR GRAVE NO DISTRITO FEDERAL

BRASÍLIA 


\author{
UNIVERSIDADE DE BRASÍLIA \\ FACULDADE DE CIÊNCIAS DA SAÚDE \\ PROGRAMA DE PÓS-GRADUAÇÃO DE SAÚDE COLETIVA
}

ANA LILIAN BISPO DOS SANTOS

ASSOCIAÇÃO ENTRE FATORES DE RISCO EOCORRÊNCIA DE DOENÇAS CRÔNICAS COM INSEGURANÇA ALIMENTAR GRAVE NO DISTRITO FEDERAL

Dissertação apresentada como requisito parcial para a obtenção do Título de Mestre em Saúde Coletiva pelo Programa de Pós-Graduação em Saúde Coletiva da Universidade de Brasília.

Orientadora: $\operatorname{Prof}^{\mathrm{a}}{ }^{\mathrm{D}} \mathrm{r}^{\mathrm{a}}$ Muriel B. Gubert

BRASÍLIA 


\title{
ASSOCIAÇÃO ENTRE FATORES DE RISCO E OCORRÊNCIA DE DOENÇAS CRÔNICAS COM INSEGURANÇA ALIMENTAR GRAVE NO DISTRITO FEDERAL
}

Dissertação apresentada como requisito parcial para a obtenção do Título de Mestre em Saúde Coletiva pelo Programa de Pós-Graduação em Saúde Coletiva da Universidade de Brasília.

BANCA EXAMINADORA

Dr ${ }^{\mathrm{a}}$ Muriel Bauermann Gubert (presidente)

Universidade de Brasília - UnB

Dr ${ }^{\mathrm{a}}$ Daniela Sanches Frozi

Fundação Oswaldo Cruz - Fiocruz Brasília

\author{
Drª Leonor Maria Pacheco Santos \\ Universidade de Brasília - UnB \\ Drª Maria da Graça Luderitz Hoefel \\ Universidade de Brasília - UnB
}


Dedico este trabalho a DEUS, que me deu a oportunidade da vida.

E a todos os moradores do Distrito Federal, que confiaram na seriedade do meu trabalho e aceitaram participar desta pesquisa. 


\section{AGRADECIMENTOS}

Aos meus queridos e amados pais, Ailton e Neuza, que me deram todo o apoio e os recursos necessários para que pudesse vencer mais um desafio.

À minha orientadora Prof ${ }^{a}$ Drª Muriel Bauermann Gubert, cujo entusiasmo e dedicação à pesquisa, são, para mim, exemplo a ser seguido ao longo de minha vida acadêmica.

A todos que, direta ou indiretamente, contribuíram para a conclusão do meu mestrado: MEU MUITO OBRIGADA!!! 
"O Senhor é a minha rocha, a minha fortaleza e o meu libertador; o meu Deus, o meu rochedo, em quem me refúgio; o meu escudo, a força da minha salvação e o meu alto refúgio." (Bíblia Sagrada - Salmos 18:2) 


\section{RESUMO}

A insegurança alimentar (IA) é realidade comum entre as famílias pobres em muitos países, sendo considerada importante determinante de doenças. No Brasil a IA tem sido associada à obesidade, porém ainda são escassos os aspectos relacionados a outras doenças crônicas não transmissíveis (DCNT). O objetivo deste trabalho foi analisar a associação entre fatores de risco e a ocorrência de DCNT com segurança alimentar (SA) e IA grave (IAG) no Distrito Federal (DF). Realizou-se um estudo transversal, durante os meses de fevereiro a junho de 2014, em pontos de grande fluxo de pessoas. A amostra foi representativa para a população adulta do DF para as condições de SA ( $n=240)$ e IAG $(n=84)$. Os dados foram coletados por meio de aplicação de questionário com perguntas fechadas referentes a características demográficas e socioeconômicas dos indivíduos, padrão alimentar e de atividade física associados à ocorrência de DCNT, peso e altura referidos, frequência do consumo de bebidas alcoólicas, referência a diagnóstico médico anterior de DCNT (doença cardiovascular, diabetes e câncer) e situação de segurança alimentar.A análise ajustada foi realizada por meio de regressão logística e expressa em odds ratio. O nível de significância considerado foi de $5 \%$. Os resultados deste trabalho apontam uma tendência de associação positiva da IAG com doença cardiovascular DCV (OR:1,79; IC 95\%: 1,01 - 3,15), consumo de carnes com excesso de gordura (OR: 2,11; IC 95\%: 1,23 - 3,64) e obesidade (OR: 2,11; IC 95\%: 1,16 - 4,22). Essa associação passa a ser negativa para as variáveis relacionadas a comportamento protetivo contra DCNT, como a prática de atividade física (OR: 0,45; IC 95\%: 0,24 0,82), consumo de feijão (OR: 0,47; IC 95\%: 0,28 - 0,79), frutas (OR: 0,19; IC 95\%: $0,04-0,79$ ) e hortaliças (OR: 0,44; IC 95\%: 0,22 - 0,89). Este trabalho evidencia a existência da tendência de associação da IAG com DCV, e sugere uma possível associação com diabetes e câncer, o que não pode ser comprovado. Há também uma relação entre IAG e fatores de risco para DCNT, relacionados ao consumo alimentar inadequado e sedentarismo.

Palavras-chave: segurança alimentar; doenças crônicas; alimentação; fome. 


\begin{abstract}
Food insecurity (FI) is common reality among poor families in many countries and is considered important determinant of diseases. In Brazil, the FI has been linked to obesity, but are still few aspects related to other chronic diseases (CD). The objective of this study was to analyze the association between risk factors and the occurrence of CDs with food security (FS) and severe FI(FIS) in the Federal District (FD). We conducted a cross-sectional study, during the months from February to June 2014, at points of large flux of people. The sample was representative of the adult population of the FD to the conditions of FS $(n=240)$ and FIS $(n=84)$. Data were collected through a questionnaire with closed questions pertaining to demographic and socioeconomic characteristics of individuals, dietary patterns and physical activity associated with the occurrence of $\mathrm{CD}$, weight and height, beverage consumption frequency alcoholic, reported prior medical diagnosis of CD (cardiovascular disease, diabetes mellitus and neoplasms) and food security situation. Adjusted analysis was performed using logistic regression and expressed as odds ratios. The significance level was 5\%. These results suggest a positive association trend of FIS with cardiovascular disease - CVD (OR: 1.79; 95\% Cl: 1.01 to 3.15), meat consumption with excess fat (OR: $2.11 ; 95 \% \mathrm{Cl}: 1.23$ to 3.64 ) and obesity (OR: 2.11 ; 95\% Cl: 1.16 to 4.22). This association becomes negative for the variables related to protective behavior against $C D$, such as physical activity (OR: $0.45 ; 95 \% \mathrm{Cl}: 0.24$ to 0.82 ), consumption of beans (OR: 0,$47 ; 95 \% \mathrm{Cl}: 0.28$ to 0.79 ), fruit (OR: $0.19 ; 95 \% \mathrm{Cl}$ : 0.04 to 0.79 ) and vegetables (OR: $0.44 ; 95 \% \mathrm{Cl}: 0.22$ to 0.89 ). This work shows the existence of the association tendency of FIS with CVD, and suggests a possible association with diabetes and cancer, which can not be proven. There is also a relationship between FIS and risk factors for $\mathrm{CD}$, related to inadequate dietary intake and sedentary lifestyle.
\end{abstract}

Key words: food security; chronic disease; feeding; hunger. 


\section{LISTA DE FIGURAS}

Quadro 1. Tamanho da amostra para erro máximo de $10 \%$ e nível de confiança de $95 \%$

Quadro 2. Descrição da pontuação utilizada para cálculo do escore de alimentação saudável

ARTIGO DE REVISÃO

Figura 1. Distribuição por década das publicações referentes à segurança alimentar e doenças crônicas no período de 1993 a 2013 (n=35)

Figura 2. Ciclo de relação entre insegurança alimentar e doenças crônicas ..... 32

Quadro 1. Estudos sobre insegurança alimentar (IA) e doenças crônicas não transmissíveis (DCNT) conduzidos em diversos países 


\section{LISTA DE TABELAS}

\section{ARTIGO ORIGINAL}

Tabela 1. Características demográficas, de saúde, consumo alimentar e situação de segurança alimentar da população do Distrito Federal $(n=324), 2014$

Tabela 2. Prevalência bruta e odds ratios brutos e ajustados para a associação entre IAG e DCNT ( $n_{S A}=240$ e $\left.n_{I A G}=84\right)$. Distrito Federal, 2014

Tabela 3. Prevalência bruta e odds ratios brutos e ajustados para a associação

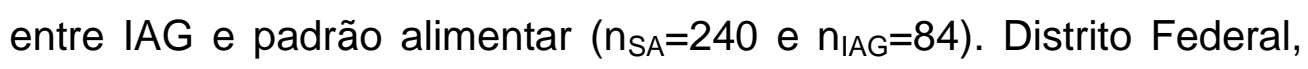
2014

Tabela 4. Prevalência bruta e odds ratios brutos e ajustados para a associação entre IAG e estado nutricional, atividade física e consumo de bebida alcoólica $\left(n_{S A}=240\right.$ e $\left.n_{I A G}=84\right)$. Distrito Federal, 2014 


\section{LISTA DE ABREVIATURAS E SIGLAS}

BVS - Biblioteca Virtual em Saúde

DCNT - Doenças crônicas não transmissíveis

DeCS - Descritores em Ciências da Saúde

DF - Distrito Federal

EBIA - Escala Brasileira de Insegurança Alimentar

FAO - Organização das Nações Unidas para a Alimentação e Agricultura

IA - Insegurança alimentar

IAG - Insegurança alimentar grave

IBGE - Instituto Brasileiro de Geografia e Estatística

IPEA - Instituto Nacional de Pesquisa Econômica Aplicada

PNAD - Pesquisa Nacional por Amostra de Domicílios

SA - Segurança alimentar

SPSS - Statistical Package for the Social Sciences

VIGITEL - Vigilância de Fatores de Risco e Proteção para Doenças Crônicas por Inquérito Telefônico

ARTIGO ORIGINAL

DCV - Doença cardiovascular

PCR - Proteína C-reativa 


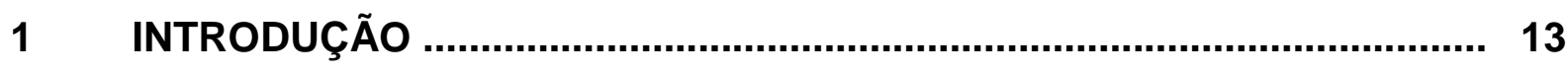

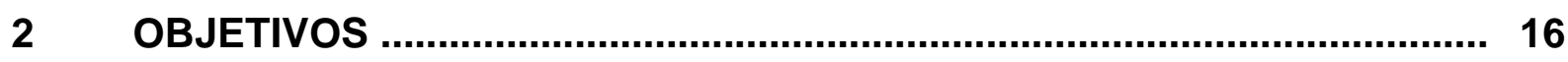

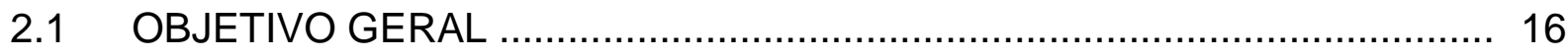

2.2 OBJETIVOS ESPECÍFICOS ……................................................ 16

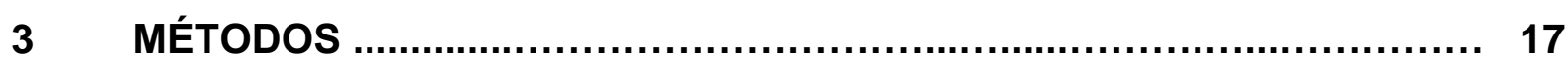

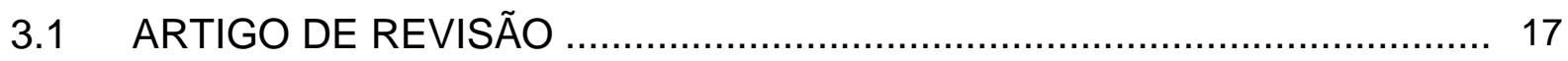

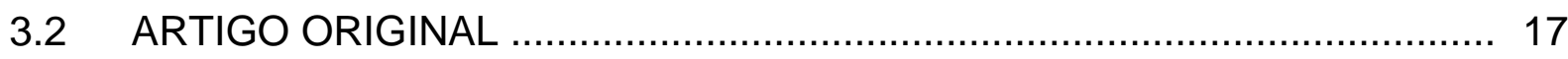

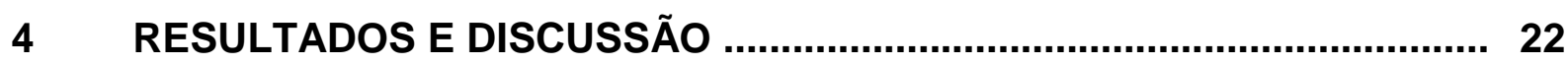

4.1 ARTIGO 1 - "INSEGURANÇA ALIMENTAR E DOENÇAS CRÔNICAS: UMA REVISÃO DA LITERATURA" ....................................................... 22

4.2 ARTIGO 2 - "ASSOCIAÇÃO ENTRE FATORES DE RISCO EOCORRÊNCIA DE DOENÇAS CRÔNICAS COM INSEGURANÇA ALIMENTAR GRAVE NO DISTRITO FEDERAL” ...................................... 40

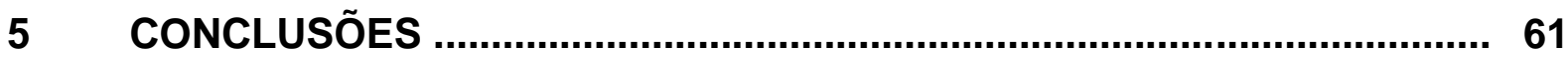

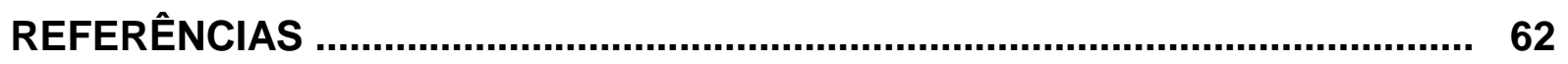


APÊNDICES

65

APÊNDICE A - QUESTIONÁRIO 66

APÊNDICE B - TERMO DE CONSENTIMENTO LIVRE E ESCLARECIDO 70

ANEXOS

ANEXO A - PARECER CONSUBSTANCIADO DO COMITÊ DE ÉTICA EM PESQUISA 


\section{INTRODUÇÃO}

Entende-se por segurança alimentar (SA) o direito de acesso aos alimentos, qualitativa e quantitativamente suficientes, a fim de garantir a sobrevivência do indivíduo sem interferir em outras necessidades essenciais. Esse acesso deve promover práticas alimentares que respeitem, de forma sustentável, a diversidade cultural, econômica e social de cada indivíduo'. Quando a SA é comprometida, pode-se dizer que a pessoa encontra-se em situação de insegurança alimentar (IA).

De acordo com Pérez-Escamilla e Segall-Corrêa ${ }^{2}$, existem cinco métodos de análise da situação de $S A$ comumente empregados em inquéritos nacionais: 1) método da FAO de cálculo da disponibilidade calórica diária per capita; 2) cálculo da renda mínima para consumo alimentar e não alimentar; 3) cálculo do consumo alimentar, como os recordatórios alimentares de 24 horas, frequência de consumo alimentar ou a quantificação dos gastos familiares com aquisição de alimentos; 4) antropometria e; 5) escalas psicométricas do acesso familiar aos alimentos, como a Escala Brasileira de Insegurança Alimentar (EBIA).

Uma vantagem do uso das escalas psicométricas é que elas medem o fenômeno diretamente a partir da experiência de IA vivenciada e percebida pelas pessoas afetadas. Captam não só a dificuldade de acesso aos alimentos, mas também a dimensão psicossocial da IA, tomando os domicílios como unidade de análise. Além disso, podem ser adaptadas, mediante utilização de metodologias qualitativas, a diferentes contextos socioculturais locais, sendo sua aplicação e análise relativamente simples ${ }^{3}$.

A IA, no domicílio, ocorre em diferentes graus de severidade e pode ser classificada como: leve, moderada e grave. A leve se caracteriza pela incerteza quanto ao acesso aos alimentos no futuro. A moderada apresenta redução quantitativa de alimentos, principalmente entre os adultos. A grave se refere à redução quantitativa de alimentos entre as crianças ou à presença da fome, quando algum indivíduo fica o dia inteiro sem comer por falta de dinheiro ${ }^{3}$.

De acordo com o Relatório de Insegurança Alimentar no Mundo, publicado em 2014 pela Organização das Nações Unidas para a Alimentação e Agricultura (FAO), a fome, a desnutrição e a subalimentação têm sido reduzidas em diversos países do mundo. $O$ indicador de prevalência de subalimentação, medida empregada pela 
FAO há cinquenta anos para dimensionar e acompanhar a fome em nível internacional, teve seus valores reduzidos entre os anos de 1990 e 2014: no Mundo (de 18,7\% para 11,3\%); na América Latina (de 15,3\% para 6,1\%); e no Brasil (de $14,8 \%$ para $<5,0 \%)^{4}$.

Esses resultados concordam com diversos estudos na temática, que utilizaram diferentes indicadores para aferição da fome, como o Relatório Nacional de Acompanhamento dos Objetivos de Desenvolvimento do Milênio ${ }^{5}$, elaborado pelo Instituto Nacional de Pesquisa Econômica Aplicada (IPEA) em 2014. Segundo o IPEA, a parcela da população brasileira na linha de extrema pobreza passou de 25,5\% (1990) para 3,5\% (2012). Considerando o estado nutricional, a prevalência de déficit de altura em crianças menores de cinco anos de idade reduziu de $13,4 \%$, em 1996, para 6,7\%, em $2006^{5}$.

A Pesquisa Nacional por Amostra de Domicílios (PNAD) ${ }^{6}$, realizada nos anos de 2004, 2009 e 2013 pelo Instituto Brasileiro de Geografia e Estatística (IBGE), utilizou em seu suplemento sobre segurança alimentar, a EBIA. Tal pesquisa visava estimar a prevalência de domicílios inseguros no país e revelou as seguintes reduções no período em questão: de $34,9 \%$ para $22,6 \%$, no Brasil; de $31,1 \%$ para $18,2 \%$, na região Centro-Oeste; e de $24,9 \%$ para $13,3 \%$, no Distrito Federal.Cabe mencionar que o instrumento utilizado nesta pesquisa, uma escala psicométrica do acesso familiar aos alimentos, apresenta maior sensibilidade, quando comparado aos utilizados para construção dos indicadores mencionados anteriormente.

Os dados apresentados, de uma forma geral, sinalizam progresso nas reduções da fome e da desnutrição, tanto a nível mundial, quanto nacional. Contudo, a IA ainda é um desafio a ser superado.

Neste cenário, ganha destaque a outra face da má alimentação causada pela IA: o excesso de peso e a obesidade. Esses dois vilões têm suas prevalências aumentadas mundialmente, incluindo países em desenvolvimento como o Brasil. Tal fato se explica pela complexidade da IA, uma vez que, paradoxalmente, ela pode acarretar tanto a desnutrição, quanto o sobrepeso e a obesidade. A explicação desse paradoxo se deve ao desencadeamento de práticas de adaptações dietéticas inapropriadas, com estratégias compensatórias, durante a adequação alimentar e a escassez de alimentos ${ }^{6-9}$.

Há indícios de que IA atual também pode apresentar relação causal com doenças crônicas não transmissíveis $(\mathrm{DCNT})^{10}$. Esse tipo de doença é um problema 
de saúde global e uma ameaça ao desenvolvimento humano. A carga das DCNT recai especialmente sobre países de baixa e média renda ${ }^{11}$, que também são os mais afetados pela $I A^{4}$. As DCNT, principal fonte da carga de doenças no Brasil, foram responsáveis por $72 \%$ das mortes ocorridas em 2007 , tendo se tornado prioridade do governo na área da saúde ${ }^{12}$.

A relação entre IA e DCNT tem sido estudada em algumas populações do mundo. A hipótese seria de que a IA pode resultar no aumento do consumo de energia barata proveniente de alimentos com alta densidade calórica e na omissão de refeições, com longos períodos de jejum, muitas vezes seguidos de períodos de ingestão compulsiva de alimentos. Esse mecanismo aconteceria durante tempo suficiente para alterar o metabolismo e resultar em um balanço energético positivo. Essa compulsão alimentar leva à obesidade, que é fator de risco para o desenvolvimento de outras DCNT, dentre elas alguns tipos de câncer, diabetes, hipertensão arterial sistêmica e doenças cardiovasculares ${ }^{6,7,10,13-17}$.

No Brasil, a IA tem sido associada à obesidade, mas ainda precisa ser esclarecido se, no país, essa relação pode ser estendida à população como um todo e às doenças crônicas ${ }^{18-22}$. Sendo assim, pesquisar os aspectos relacionados a este fenômeno é de suma importância para o planejamento de futuras estratégias de intervenções nutricionais e na formulação de políticas públicas que garantam as condições de segurança alimentar da população. 


\section{OBJETIVOS}

\subsection{OBJETIVO GERAL}

Analisar a associação entre fatores de risco e ocorrência de DCNT com SA e IA grave (IAG) no Distrito Federal (DF).

\subsection{OBJETIVOS ESPECÍFICOS}

- Realizar uma revisão da literatura para elucidar a relação entre IA e DCNT;

- Identificar as prevalências de DCNT na população investigada, em situação de SA e IAG;

- Verificara prevalência de fatores de risco para DCNT na população investigada, em situação de SA e IAG. 


\section{MÉTODOS}

\subsection{ARTIGO DE REVISÃO}

Foi realizada uma revisão bibliográfica, selecionando artigos originais e de revisão publicados em revistas disponibilizadas no Portal de Periódicos da Capes. Para seleção, foram consideradas publicações dos últimos 20 anos, listadas a partir dos descritores indexados no DeCS/BVS, descritores em ciências da saúde/biblioteca virtual em saúde: segurança alimentar e nutricional e doenças crônicas, nos idiomas português, inglês e espanhol.

Artigos que abordavam os temas segurança alimentar e doenças crônicas foram incluídos, excluindo-se aqueles que não tratavam especificamente do assunto.

Em um primeiro momento foram selecionados 519 artigos. 17 duplicações foram excluídas. Realizou-se uma leitura inicial dos resumos dos 502 artigos restantes para constatar a coerência com os critérios de inclusão. Finalmente, 35 artigos foram incluídos para comporem a revisão de literatura, os quais foram submetidos a uma leitura mais aprofundada. Posteriormente, os conteúdos destes artigos foram agrupados de acordo com os assuntos: aspectos gerais da IA; relações entre IA e DCNT; e estudos sobre IA e DCNT conduzidos no Brasil e em outros países.

\subsection{ARTIGO ORIGINAL}

Trata-se de um estudo transversal, descritivo e analítico, que busca verificar a associação entre insegurança alimentar e presença de DCNT e seus fatores de risco.

A pesquisa foi realizada durante os meses de fevereiro a junho de 2014 , em quatro pontos de grande fluxo de pessoas do DF: rodoviárias do Plano Piloto, de Taguatinga e da Ceilândia, bem como Estação Shopping do Metrô DF. 
Foi utilizada uma amostra representativa por cota para a população adulta do DF em condições de SA e IAG.

O cálculo do tamanho amostral baseou-se em amostragem aleatória estratificada por faixa de renda domiciliar per capita, capaz de gerar representatividade tanto para pessoas em situação de SA, quanto para aquelas em situação de IAG (Quadro1), estimada a partir de dados da Pesquisa Nacional por Amostra de Domicílio2004/200923. Foi estabelecido um tamanho amostral total de 324 indivíduos residentes no DF, 240 classificados no estrato de SA e 84 no estrado de IAG. Para o cálculo do tamanho da amostra, o erro máximo estabelecido foi $10 \%$, com nível de confiança igual 95\%.

Quadro 1. Tamanho da amostra para erro máximo de $10 \%$ e nível de confiança de $95 \%$.

\begin{tabular}{|l|c|c|}
\hline \multicolumn{1}{|c|}{ Classes de rendimento mensal domiciliar per capita } & SA & IAG \\
\hline Até $1 / 4$ do SM (até $\mathrm{R} \$ 181,00)$ & 4 & 22 \\
\hline Mais de $1 / 4$ a $1 / 2$ do SM (mais de $\mathrm{R} \$ 181,00$ a $\mathrm{R} \$ 362,00)$ & 19 & 29 \\
\hline Mais de $1 / 2$ a 1 SM (mais de $\mathrm{R} \$ 362,00$ a $\mathrm{R} \$ 724,00)$ & 49 & 23 \\
\hline Mais de 1 a 2 SM (mais de $\mathrm{R} \$ 724,00$ a $\mathrm{R} \$ 1.448,00)$ & 60 & 7 \\
\hline Mais de 2 SM (mais de $\mathrm{R} \$ 1.448,00)$ & 108 & 3 \\
\hline Total & $\mathbf{2 4 0}$ & $\mathbf{8 4}$ \\
\hline
\end{tabular}

Com o intuito de testar o instrumento foi realizada uma pesquisa piloto antes do início definitivo da coleta de dados.

Os dados foram coletados por meio de aplicação de questionário com perguntas fechadas, que foi preenchido por equipe devidamente treinada. Os indivíduos que aceitaram participar da pesquisa foram submetidos a uma triagem para identificação da situação de segurança alimentar e classe de rendimento mensal per capita, a fim de comporem a amostra estratificada segundo esses parâmetros. Foram adotados os seguintes critérios de inclusão: ter idade igual ou superior a 18 anos, residir no DF, ter conhecimento sobre a disponibilidade de alimentos no domicílio, ter situação de SA ou IAG. Mulheres grávidas, pessoas com incapacidade cognitiva, surdos e mudos foram excluídos da amostra.

O questionário (apêndice $A$ ) foi composto por perguntas oriundas da EBIA e do sistema de Vigilância de Fatores de Risco e Proteção para Doenças Crônicas por 
Inquérito Telefônico (VIGITEL). Essas perguntas já foram validadas na população brasileira pelo Ministério da Saúde nos anos de 2009 e 2011, respectivamente ${ }^{23,24}$.

As perguntas do questionário, curtas e simples, abordaram: a) características demográficas e socioeconômicas dos indivíduos; b) características do padrão alimentar e de atividade física associadas à ocorrência de DCNT; c) peso e altura referidos; d) frequência do consumo de bebidas alcoólicas; e) referência a diagnóstico médico anterior de DCNT; e f) situação de segurança alimentar.

Para verificar a ocorrência de DCNT, utilizou-se a variável de diagnóstico médico prévio de diabetes, doença cardiovascular (insuficiências cardíacas congestivas, acidente vascular cerebral, infarto agudo do miocárdio, arritmias cardíacas, isquemias, anginas, hipertensão arterial sistêmica) e câncer.

$\mathrm{Na}$ identificação da ocorrência de fatores de risco para DCNT, utilizou-se a prevalência de adultos com excesso de peso (índice de massa corporal $\geq 25 \mathrm{~kg} / \mathrm{m}^{2}$ ) e obesidade (índice de massa corporal $\geq 30 \mathrm{~kg} / \mathrm{m}^{2}$ ); consumo de alimentos considerados marcadores de padrões saudáveis: feijão ( $\geq 1 x / d i a)$, fruta ( $\geq 3 x / d i a)$ e hortaliça ( $\geq 3 x / d i a)$,e não saudáveis: carnes com excesso de gordura, leite com teor integral de gordura e refrigerante normal;prática recomendada de atividade física no tempo livre ( $\geq 150 \mathrm{~min} . /$ semana);consumo abusivo de bebidas alcoólicas ( $q$ : $>4$ doses/ocasião e $\delta$ : $>$ 5doses/ocasião).

Embora a obesidade seja um tipo de doença crônica, neste estudo ela foi considerada fator de risco para o desenvolvimento de outras DCNT relacionadas à dieta inadequada ${ }^{3,6,7,17}$.

Para mensuração da situação de segurança alimentar foi utilizada a prevalência de domicílios classificados como seguros e inseguros grave.

As respostas dadas as perguntas do questionário referentes à situação de segurança alimentar foram pontuadas e classificadas em SA ou IAG, sendo considerado domicílios seguros aqueles com 0 pontos (presença ou não de moradores menores de 18 anos) e inseguros grave aqueles com 10 a 14 pontos (presença de moradores menores de 18 anos) ou com 6 a 8 pontos (ausência de moradores menores de 18 anos).

Um escore de alimentação saudável foi elaborado para avaliar as questões marcadoras do inquérito, incluindo as variáveis feijão, frutas, verduras cruas, legumes cozidos, leite e refrigerante, em quatro níveis de frequência de consumo 
semanal, conforme descrito no quadro 2. O escore foi calculado a partir da soma da pontuação dos itens, podendo variar de 0 a $24^{25}$.

A análise estatística dos dados foi realizada mediante a descrição das variáveis estudadas caracterizando, dessa forma, a amostra levantada. As variáveis foram inseridas e analisadas no programa SPSS Statistics versão 20.

A descrição da amostra foi realizada por meio de análise univariada. As estimativas fornecidas pela análise bivariada de variáveis categóricas foram expressas por prevalências e intervalos de confiança de $95 \%$, sendo utilizado teste do qui-quadrado para comparação entre as variáveis categóricas. A análise ajustada foi realizada por meio de regressão logística e expressa em odds ratio (OR), sendo as variáveis consideradas no modelo para o ajuste biológico: sexo, idade e raça; e o ajuste social: escolaridade e renda. Para comparação de média dos escores de alimentação saudável foi utilizado o teste t-student. O nível de significância considerado foi de $5 \%$.

Atendendo ao que estabelece a resolução nํ 466, de 12 de dezembro de 2012, do Conselho Nacional de Saúde, esta pesquisa leva em conta os princípios éticos de respeito pela autonomia das pessoas, bem como a obrigação ética de aumentar ao máximo os benefícios e reduzir ao mínimo os danos. O presente estudo foi aprovado pelo Comitê de Ética em Pesquisa da Universidade de Brasília sob o protocolo n 18340813.8 .0000 .0030 , conforme parecer consubstanciado de 12 de setembro de 2013 (Anexo A). Os indivíduos que aceitaram participar da pesquisa assinaram o Termo de Consentimento Livre e Esclarecido (Apêndice B). 
Quadro 2. Descrição da pontuação utilizada para cálculo do escore de alimentação saudável.

\begin{tabular}{|c|c|c|c|c|c|}
\hline & 0 & 1 & 2 & 3 & 4 \\
\hline Feijão & $\begin{array}{c}\text { Nunca/quase } \\
\text { nunca }\end{array}$ & $1-2 x /$ semana & $3-4 x /$ semana & $5-6 x /$ semana & Todos os dias \\
\hline Fruta & $\begin{array}{c}\text { Nunca/quase } \\
\text { nunca }\end{array}$ & $1-2 x /$ semana & $3-4 x /$ semana & $\begin{array}{l}\text { Todos os dias ou } \\
5-6 x / \text { semana e } \\
1-2 x / \text { dia }\end{array}$ & $\begin{array}{l}\text { Todos os dias ou } \\
5-6 x / \text { semana e } \\
\geq 3 x / \text { dia }\end{array}$ \\
\hline Verdura crua & $\begin{array}{c}\text { Nunca/quase } \\
\text { nunca }\end{array}$ & $1-2 x /$ semana & $3-4 x /$ semana & $\begin{array}{l}\text { Todos os dias ou } \\
5-6 x / \text { semana e } \\
1 \text { x/dia }\end{array}$ & $\begin{array}{l}\text { Todos os dias ou } \\
5-6 x / \text { semana } \mathrm{e} \\
\geq 2 \times / \text { dia }\end{array}$ \\
\hline $\begin{array}{l}\text { Legumes } \\
\text { cozidos }\end{array}$ & $\begin{array}{c}\text { Nunca/quase } \\
\text { nunca }\end{array}$ & $1-2 x /$ semana & $3-4 x /$ semana & $\begin{array}{l}\text { Todos os dias ou } \\
5-6 x / \text { semana } \mathrm{e} \\
1 \text { x/dia }\end{array}$ & $\begin{array}{l}\text { Todos os dias ou } \\
5-6 x / \text { semana } \mathrm{e} \\
\geq 2 \times / \text { dia }\end{array}$ \\
\hline Leite & $\begin{array}{c}\text { Nunca/quase } \\
\text { nunca }\end{array}$ & $1-2 x /$ semana & $3-4 x /$ semana & $5-6 x /$ semana & Todos os dias \\
\hline Refrigerante & $\begin{array}{l}\text { Todos os } \\
\text { dias }\end{array}$ & $5-6 x /$ semana & $3-4 x /$ semana & $1-2 x /$ semana & $\begin{array}{c}\text { Nunca/quase } \\
\text { nunca e diet/light }\end{array}$ \\
\hline
\end{tabular}

Fonte: Souza ${ }^{2 b}$. 


\section{RESULTADOS E DISCUSSÃO}

Os resultados serão apresentados na forma de dois artigos científicos, compreendendo um artigo de revisão "Insegurança alimentar e doenças crônicas: uma revisão da literatura" e um artigo original "Associação entre fatores de risco e ocorrência de doenças crônicas com insegurança alimentar no Distrito Federal".

\subsection{ARTIGO 1 - "INSEGURANÇA ALIMENTAR E DOENÇAS CRÔNICAS: UMA REVISÃO DA LITERATURA"}

Submetido à revista Tempus Actas de Saúde Coletiva

Ana Lilian Bispo dos Santos, Muriel Bauermann Gubert

\section{RESUMO}

Foi realizada uma análise da literatura, baseada em evidências científicas, para elucidar a relação entre insegurança alimentar (IA) e doenças crônicas não transmissíveis (DCNT). Artigos originais e de revisão foram consultados, atentandose aos publicados nos últimos 20 anos em revistas científicas internacionais disponibilizadas no Portal de Periódicos da Capes. Foram utilizados os descritores indexados no DeCS/BVS: segurança alimentar e nutricional e doenças crônicas, nos idiomas português, inglês e espanhol. 35 artigos foram selecionados, sendo $57,1 \%$ $(n=20)$ publicados entre os anos de 2010 e 2013. Observou-se que o número de publicações aumentou nas últimas 2 décadas, evidenciando o crescente interesse dos pesquisadores em conduzir estudos sobre a segurança alimentar e DCNT. A análise qualitativa dos conteúdos apontou existência de relação de influência da IA na causa e no controle das DCNT, devido a adaptações dietéticas inadequadas desencadeadas pela IA, com estratégias compensatórias durante a adequação alimentar e a escassez de alimentos, levando ao quadro de obesidade, hipertensão e diabetes. Este quadro prejudica a capacidade de autogestão da doença, além de gerar demandas conflitantes, que por sua vez aumentam a vulnerabilidade econômica, mental, física e social, fechando o ciclo de relação entre a IA e a DCNT.

Palavras-chave: doença crônica; segurança alimentar e nutricional; alimentação; fome. 


\begin{abstract}
Was realize an analysis of the literature, based on scientific evidence, to elucidate the relationship between food insecurity $(\mathrm{FI})$ and chronic diseases $(\mathrm{CD})$. Original and review articles were consulted, paying attention to those published in the last 20 years in international scientific journals available in Periodical Portal Capes. Were used indexed descriptors in MeSH/VHL: food and nutrition security and chronic diseases, in portuguese, english and spanish languages. 35 articles were selected, 57.1\% $(n=20)$ published between 2010 and 2013. Observed that the number of publications has increased over the past 2 decades, reflecting the growing interest of researchers in conducting studies on the safety feed and $\mathrm{CD}$. The qualitative content analysis indicated there was a relationship of influence of $\mathrm{Fl}$ in the cause and control of $\mathrm{CD}$ due to inadequate dietary adaptations triggered by $\mathrm{FI}$ with compensatory strategies during food adequacy and food shortages, leading to the picture of obesity, hypertension and diabetes. This picture impairs the ability of self-management of the disease, beyond of generate conflicting demands, which in turn increases the economic vulnerability, mental, physical and social, closing the cycle of relationship between $\mathrm{FI}$ and $\mathrm{CD}$.
\end{abstract}

Key words: chronic disease; food security; feeding; hunger.

Introdução

A Organização Mundial da Saúde afirma que o estado de saúde de um indivíduo é influenciado por fatores sociais, econômicos, políticos e ambientais. Alguns fatores como pobreza, exclusão social, condições precárias de moradia e insegurança alimentar (IA) são importantes determinantes da maioria das doenças em diversos países ${ }^{1}$.

A IA é um problema mundial, fenômeno comum entre as famílias pobres em muitos países desenvolvidos e em desenvolvimento. Embora o Brasil tenha avançado nas ações de segurança alimentar e nutricional adotando estratégias de transferência de renda, de apoio à agricultura familiar e ações para universalização 
do acesso à água no Semiárido, ainda existem 65,6 milhões de brasileiros residentes em 17,7 milhões de domicílios, que apresentam alguma restrição alimentar ou, pelo menos, alguma preocupação com a possibilidade de ocorrer restrição devido à falta de recursos para adquirir alimentos, caracterizando o estado de $\mid A^{2-4}$.

Fome e IA desafiam o bem-estar de crianças, adultos, famílias e comunidades. Os resultados negativos dessa insegurança, em todo o curso da vida, incluem deficiências físicas, obesidade entre as mulheres, sofrimento psicológico e distúrbios sócios familiares. Esses resultados representam um grave, mas evitável, problema de saúde pública ${ }^{3}$.

O novo perfil epidemiológico da população brasileira revela uma fase de transição com predominância das doenças crônicas não transmissíveis (DCNT), cuja morbimortalidade está associada à alimentação, nutrição e estilo de vida. Sabe-se que as doenças associadas à má alimentação, como diabetes mellitus e hipertensão arterial sistêmica são também acarretadas pela falta de segurança alimentar e nutricional, uma vez que, além dos fatores genéticos, há fatores alimentares na gênese dessas patologias, as quais requerem, no seu tratamento, medidas que vão além do uso de medicamentos e incluem mudanças no hábito alimentar e estilo de vida 5 .

Cabe ressaltar a complexidade da IA, uma vez que, paradoxalmente, ela pode acarretar tanto a desnutrição quanto sobrepeso e obesidade ${ }^{6}$. Estima-se que até o ano de 2015 as DCNT associadas à superalimentação (fenômeno muitas vezes presente na IA, quando o individuo se superalimenta de alimentos energeticamente densos e mais baratos) irão superar a desnutrição como as principais causas de morte em comunidades de baixa renda. Por isso, é necessário estudar a dupla carga da má nutrição causada pela pobreza, fome e $\mathrm{IA}^{6}$. Sendo assim, o presente estudo tem o objetivo de realizar uma revisão da literatura para elucidar a relação entre IA e DCNT.

Métodos

Foi realizada, em setembro de 2013, uma análise de artigos originais e de revisão publicados em revistas disponibilizadas no Portal de Periódicos da Capes, 
que reúne atualmente mais de 35 mil exemplares das melhores produções científicas internacionais. Foram selecionadas publicações dos últimos 20 anos, utilizando-se os descritores indexados no DeCS/BVS: segurança alimentar e nutricional e doenças crônicas, nos idiomas português, inglês e espanhol.

Como critérios de inclusão, foram considerados os artigos que abordassem os temas segurança alimentar e doenças crônicas, excluindo-se os artigos que não tratavam especificamente dos temas.

Após a seleção dos artigos, realizou-se uma leitura inicial dos resumos obtidos para constatar a coerência com o tema a ser pesquisado e com os critérios de inclusão. Foram selecionados 35 artigos pertinentes ao tema para comporem a revisão de literatura, os quais foram submetidos a uma leitura mais aprofundada. Posteriormente, os conteúdos dos artigos foram agrupados de acordo com os assuntos: aspectos gerais da IA; relações entre IA e DCNT; e estudos sobre IA e DCNT conduzidos no Brasil e em outros países.

Resultados e discussão

A busca em bases de dados gerou um total de 519 artigos, sendo 11 escritos em português, 499 escritos em inglês e 9 escritos em espanhol. Dentre eles, foram excluídas 17 duplicações, ou seja, na verdade, foram obtidos 502 artigos. Após análise detalhada, verificou-se que apenas 35 artigos atendiam aos critérios de inclusão.

Em percentual, foram selecionados os seguintes artigos por ano de publicação: 2,9\% ( $n=1)$ entre os anos 1993 a 1999, 40,0\% ( $n=14)$ de 2000 a 2009 e $57,1 \%(n=20)$ de 2010 a 2013. Observou-se que o número de publicações aumentou nas últimas duas décadas (Figura 1), evidenciando o crescente interesse dos pesquisadores em conduzir estudos sobre a segurança alimentar e doenças crônicas.

Aspectos gerais da insegurança alimentar

$\mathrm{Na}$ literatura os conceitos de IA convergem para a condição em que a disponibilidade de alimentos seguros e nutricionalmente adequados, ou a 
capacidade de adquirir alimentos de formas cultural e socialmente aceitáveis, é limitada ou incerta ou ainda insuficiente para uma vida ativa e saudável ${ }^{3,7-14}$.

Green-LaPierre ${ }^{9}$ menciona em seus estudos a existência de duas dimensões da IA: dimensão individual e dimensão domiciliar. Cada uma dessas dimensões contém quatro componentes: quantitativo, qualitativo, psicológico e social. Os componentes quantitativos e qualitativos são os mais fáceis de serem mensurados: experimentar a fome, ficar sem comer, alteração ou redução da comida habitualmente ingerida para reduzir gastos e consumir refeições nutricionalmente inadequadas. O componente psicológico para a IA é exemplificado pela sensação de ansiedade devido à falta de recursos para adquirir alimentos. Enquanto o componente social é manifestado por padrões alimentares menos aceitáveis, social ou culturalmente (por exemplo, pular refeições), e de aquisição de alimentos de forma socialmente inaceitáveis ${ }^{9,8,12}$.

Cabe ressaltar que sentir fome, sensação física desconfortável que acompanha a falta de alimentos, não é suficiente para caracterizar um estado de IA. Muitos adultos com IA relatam que não sentem uma sensação que eles identifiquem como fome. Além disso, a sensação de fome é comum entre muitas pessoas que podem comprar alimentos, mas acessá-los com menos frequência do que gostariam, por outras razões, como regime alimentar ou prioridades concorrentes na hora da refeição ${ }^{8}$.

Dentre os principais grupos vulneráveis a IA temos: jovens de famílias de baixa renda, minorias étnicas, famílias com baixo nível de escolaridade materna, menores de idade, divorciados, viúvos e famílias com crianças ou monoparentais ${ }^{11,15,16}$. Segundo Keller ${ }^{17}$, os idosos também formam grupo vulnerável a IA, pois são mais propensos a limitações nas atividades diárias, o que pode comprometer o acesso ao alimento e consequentemente afetar o estado nutricional, acarretando prejuízos à saúde. Para Kramer-LeBlanc ${ }^{18}$ outros seguimentos da população também são vulneráveis, como mulheres grávidas e lactantes, trabalhadores migrantes, pessoas com algum tipo de doenças ou deficiências, semteto e índios. Cada grupo tem necessidades distintas e questões associadas com a obtenção adequada de alimentos.

Existe um quadro conceitual para IA específico para idosos. Este quadro inclui fatores que podem ajudar a prever ou pode levar a IA, dentre eles encontram-se 
saúde física, mobilidade restrita, limitado contato a família/assistência, seguro de saúde inadequado, falta de recurso financeiro e gastos inesperados ${ }^{17,19}$.

Para Kirkpatrick ${ }^{20}$ o local de moradia influência a vulnerabilidade a IA. O bairro que se ocupa confere vantagens e desvantagens de localização, incluindo recursos ambientais para produção de comida. Disparidades no acesso a comida em relação aos indicadores socioeconômicos, assim como áreas carentes com pouco acesso a comida saudável a preços acessíveis, são possíveis explicações para essa afirmação.

Estudos revelaram múltiplas associações entre IA e dieta ${ }^{21}$. Sabe-se que a IA pode afetar a saúde, direta ou indiretamente, por meio do estado nutricional, como indicado pela desnutrição ou supernutrição. A IA está relacionada à ingestão inadequada de macro e micronutrientes, devido a falta do consumo de dieta balanceada e diversificada. Esta situação contribui para maior prevalência de baixo peso ou sobrepeso e obesidade, maior ou menor nível de colesterol no sangue, menor nível de albumina sérica, diminuição da hemoglobina e vitamina $A$, comportamentos alimentares desordenados, depressão e comprometimento da função cognitiva ${ }^{7,11,15}$.

Insegurança alimentar e doenças crônicas não transmissíveis

As consequências da IA na saúde estão bem documentadas. Populações com IA têm maiores taxas de evolução das doenças crônicas relacionadas, incluindo obesidade, diabetes e doenças cardiovasculares ${ }^{11,13,14,21-26}$.

Jiménez-Cruz ${ }^{26}$ e Shakey ${ }^{27}$ verificaram em seus estudos que crianças com IA eram menos propensas a atender as recomendações de ingestão dietética, apresentavam consumo de maiores quantidades de gorduras saturadas, doces e frituras, bem como menor consumo de frutas, hortaliças, laticínios e carnes. Esses dados foram semelhantes aos encontrados por Robaina ${ }^{3}$ em seu estudo com adultos usuários de uma distribuidora de alimentos doados. Ele constatou que o consumo de frutas e hortaliças diminui com o aumento da IA. Tal prática alimentar pode resultar em ingestão inadequada de vitaminas, minerais e proteína de alto valor biológico, tornando o indivíduo vulnerável a vários problemas de saúde.

As estratégias para enfrentamento da IA incluem redução da quantidade e frequência das refeições e aumento da ingestão de alimentos de alta densidade 
energética e pobres em nutrientes, por serem mais acessíveis, disponíveis e baratos, além de serem altamente saborosos e promoverem maior saciedade 8,11,12,27-29. Dietas a base desses tipos de alimentos aumentam o risco de ingestão inadequada de vitamina $\mathrm{D}$, vitaminas do complexo $\mathrm{B}$, magnésio, ferro, zinco, cálcio, potássio e fibra dietética, bem como a probabilidade do consumo excessivo de açúcar, gorduras e sódio ${ }^{12,27,30}$. O que favorece o desenvolvimento da obesidade, hipertensão arterial sistêmica, hiperlipidemia, alguns tipos de cânceres e outras doenças crônicas associadas ${ }^{12,25}$.

Cheng $^{31}$ relata a IA como fator de risco para diabetes em adultos não idosos. Ela causa sintomas de ansiedade, depressão e fadiga, levando ao controle glicêmico inadequado.

Alguns estudos apontam a IA como desafio adicional para as pessoas com diabetes. Existem vários mecanismos por meio dos quais a IA é hipótese para predispor indivíduos com diabetes ao pior autocontrole da doença. Primeiro, ela pode mudar o padrão alimentar caracterizado pelo alto consumo de frutas e hortaliças para o consumo de alimentos de maior densidade calórica, com alto teor de carboidrato refinado e gordura. Estes alimentos podem trazer impacto negativo no controle da glicemia. Segundo, mudanças diárias na disponibilidade de alimentos podem resultar em paralela flutuação dos níveis de glicose no sangue, que pode dificultar o controle glicêmico. Finalmente, a IA pode reduzir a capacidade do indivíduo em executar com sucesso o autocuidado da diabetes ${ }^{32,33}$.

Existem na literatura algumas hipóteses para explicar o fenômeno cíclico da relação entre IA e DCNT, que foram resumidas na figura $2^{11,12,14}$.

\section{Estudos sobre IA e DCNT conduzidos no Brasil e em outros países}

$\mathrm{Na}$ ocasião em que foi realizada a busca de artigos científicos no Portal de Periódicos da Capes para compor a presente revisão, não foram encontradas publicações brasileiras sobre doenças crônicas entre a população exposta a IA.

Lyles $^{32}$ realizou um estudo longitudinal no estado de Missouri - Estados Unidos da América, no qual indivíduos diabéticos com IA e segurança alimentar (SA) receberam intervenção educacional sobre o autocuidado da diabetes e observou que, antes da intervenção, os indivíduos com IA apresentavam maiores valores de hemoglobina glicosilada, menor eficácia no autocuidado da doença e baixa ingestão 
de frutas e hortaliças, quando comparados aos indivíduos com SA. Após a intervenção, verificou-se que os indivíduos com IA permaneceram com menor eficácia no autocuidado da diabetes e baixa ingestão de frutas e hortaliças. Contudo, estes indivíduos foram capazes de se envolverem na intervenção educacional e apresentaram melhorias nos valores de hemoglobina glicosilada, na eficácia no autocuidado da doença e na ingestão de frutas e hortaliças.

Em estudo realizado por Mohamadpour ${ }^{7}$ na Malásia, a IA não foi um fator de risco significativo para saúde, mas esteve associada à inadequada ingestão dietética e circunferência de cintura. $O$ estudo sugeriu que o efeito da IA sobre a saúde é exercido por meio de ingestão dietética, fato que pode ter impacto na circunferência de cintura.

O quadro 1 apresenta outros estudos sobre a relação entre $S A$, qualidade da dieta e índice de massa corporal, associações entre IA e hipertensão, hiperlipidemia e diabetes, bem como relação da SA com parâmetros clínicos de vários fatores de risco para DCNT, que foram realizados em diversos países do mundo ${ }^{3,31,34,35}$.

Conclusão

Embora, por escolha metodológica, este trabalho tenha apresentado algumas limitações como as diferenças metodológicas dos estudos analisados, a falta de um tratamento estatístico para comparação dos resultados encontrados e a ausência de um método para identificação dos materiais não publicados, ele aponta para uma relação de influência da IA na causa e no controle das DCNT, devido a adaptações dietéticas inadequadas desencadeadas pela IA, com estratégias compensatórias durante a adequação alimentar e a escassez de alimentos, levando ao quadro de obesidade, hipertensão e diabetes. Este quadro prejudica a capacidade de autogestão da doença, além de gerar demandas conflitantes, que por sua vez aumentam a vulnerabilidade econômica, mental, física e social, fechando o ciclo de relação entre a IA e a DCNT.

Cabe ressaltar a necessidade de uma ação sistemática e sustentada para enfrentamento deste ciclo. Dentre as possíveis intervenções estão incluídos o adequado financiamento e aumento da utilização de programas de assistência alimentar e nutricional, a inclusão da educação alimentar e nutricional em todos os 
programas que fornecem alimentos e assistência nutricional, bem como programas de promoção da autossuficiência econômica dos indivíduos e das famílias. 


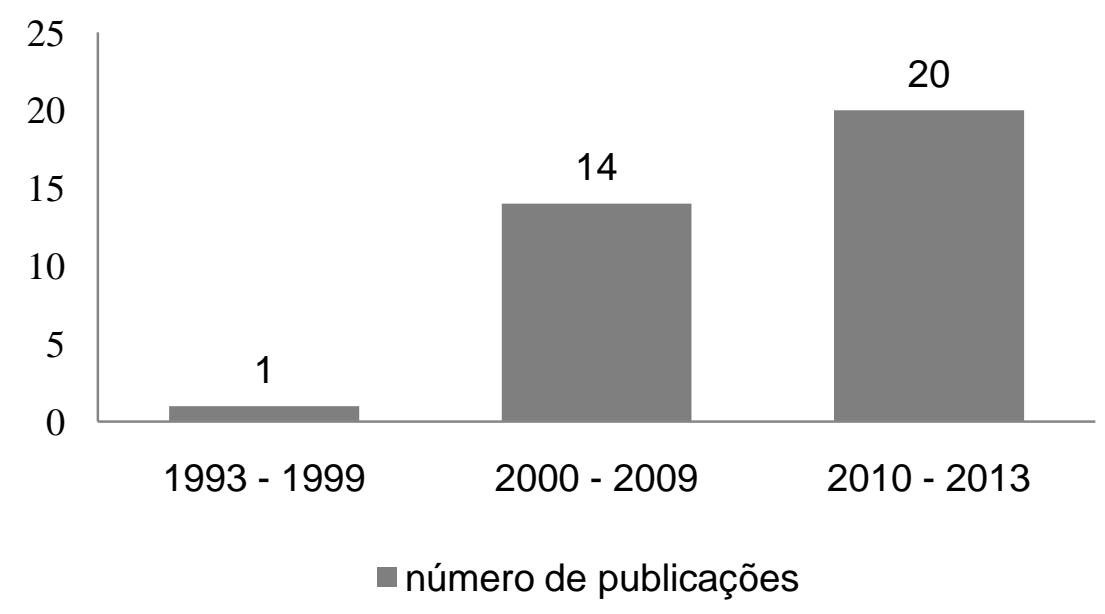

Figura 1. Distribuição por década das publicações referentes à segurança alimentar e doenças crônicas no período de 1993 a 2013 (n=35). 


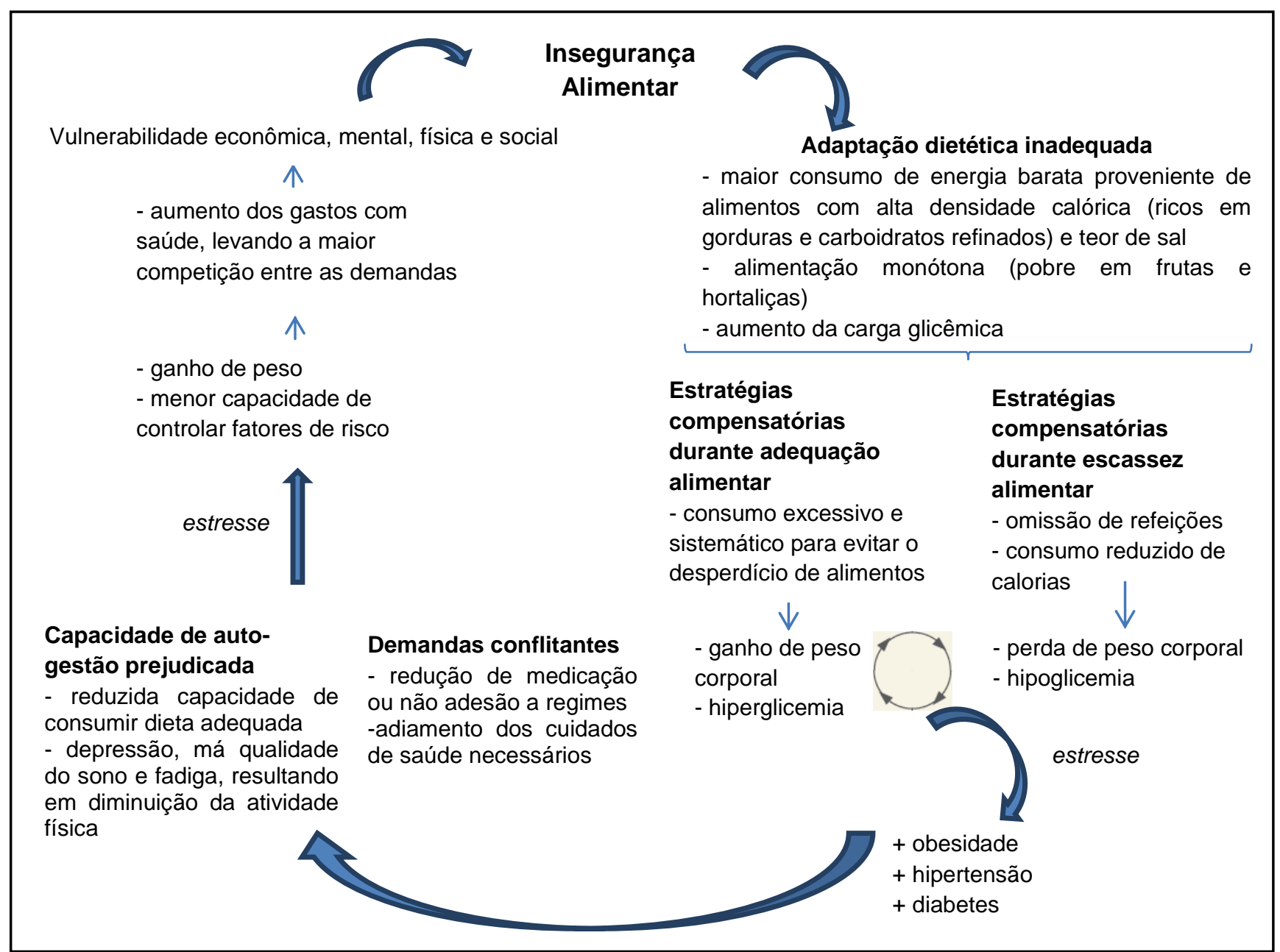

Figura 2. Ciclo de relação entre insegurança alimentar e doenças crônicas. Adaptado de Ramsey ${ }^{11}$, Seligman, Schillinger ${ }^{12}$ e Chilton ${ }^{14}$. 
Quadro 1. Estudos sobre insegurança alimentar (IA) e doenças crônicas não transmissíveis (DCNT) conduzidos em diversos países (continua).

\begin{tabular}{|c|c|c|c|c|}
\hline Referência & Local & Objetivo do estudo & População-alvo & Resultados \\
\hline Robaina $^{3}$ & $\begin{array}{l}\text { Estados Unidos da } \\
\text { América (Hartford - } \\
\text { Connecticut) }\end{array}$ & $\begin{array}{l}\text { Examinar a relação entre } \\
\text { segurança alimentar, } \\
\text { qualidade da dieta e índice } \\
\text { de massa corporal (IMC). }\end{array}$ & $\begin{array}{l}\text { - amostra: } 212 \\
\text { usuários de uma } \\
\text { distribuidora de } \\
\text { alimentos doados } \\
\text { - sexo: } 41 \% \text { masculino } \\
\text { e 59\%feminino } \\
\text { - idade: entre } 19 \text { e } 87 \\
\text { anos (média=51,9 } \\
\text { anos) }\end{array}$ & $\begin{array}{l}\text { - 84\% de IA; } \\
\text { - consumo limitado de frutas e hortaliças; } \\
\text { - IMCmédio=29,5 } \mathrm{kg} / \mathrm{m}^{2} \text {, com } 32 \% \text { de sobrepeso, } \\
29,8 \% \text { de obesos e } 10,2 \% \text { de obesidade mórbida; } \\
\text { - idade esteve positivamente associada a SA } \\
\text { ( } p<0,01 \text { ). Indivíduos com mais de } 60 \text { anos } \\
\text { apresentaram3 vezes mais } S A \text { do que indivíduos } \\
\text { mais jovens; } \\
\text { - consumo de frutas e hortaliças foi positivamente } \\
\text { associado a SA ( } p=0,02 \text { ). Indivíduos com SA } \\
\text { consumiam2 vezes mais frutas e hortaliças do que } \\
\text { indivíduos com IA ( } p=0,04 \text { ); } \\
\text { - mulheres eram } 4 \text { vezes mais obesas que os } \\
\text { homens ( } p<0,01 \text { ); } \\
\text { - IA não foi associada a obesidade nesta amostra. }\end{array}$ \\
\hline Cheng $^{31}$ & $\begin{array}{l}\text { Quênia (Eldoret, Kitale } \\
\text { and Webuye) }\end{array}$ & $\begin{array}{l}\text { Determinar a proporção e } \\
\text { características de } \\
\text { pacientes com diabetes e } \\
\text { IA em } 3 \text { hospitais públicos } \\
\text { de referência em diabetes. }\end{array}$ & $\begin{array}{l}\text { - amostra: } 1733 \\
\text { pacientes diabéticos } \\
\text { - sexo: } 45,9 \% \\
\text { masculino e } 54,1 \% \\
\text { feminino } \\
\text { - idade: entre } 4 \text { e } 92 \\
\text { anos (média=53 anos) }\end{array}$ & $\begin{array}{l}\text { - 32\% de IA; } \\
\text { - indivíduos com IA apresentaram menor valor de } \\
\text { peso }(68,6 \mathrm{~kg}) \text {, IMC }\left(26,3 \mathrm{~kg} / \mathrm{m}^{2}\right) \text {, presença de } \\
\text { cuidador } \quad(65,5 \%) \text { e utilização de insulina } \\
(46,9 \%)(\mathrm{p}<0,01) \text {. A avaliação geral da população } \\
\text { revelou concentração média elevada de HbA1c de } \\
81 \mathrm{mmol} / \mathrm{mol}(9,6 \%) \text {. }\end{array}$ \\
\hline
\end{tabular}


Quadro 1. Estudos sobre IA e DCNT conduzidos em diversos países (continuação).

\begin{tabular}{|c|c|c|c|c|}
\hline Referência & Local & Objetivo do estudo & População-alvo & Resultados \\
\hline Seligman $^{34}$ & $\begin{array}{l}\text { Estados Unidos da } \\
\text { América }\end{array}$ & $\begin{array}{l}\text { Avaliar associações entre } \\
\text { IA e hipertensão, } \\
\text { hiperlipidemia e diabetes. }\end{array}$ & $\begin{array}{lr}\text { - } & \text { amostra: } \\
\text { 5.094adultos que } \\
\text { participaram do } \\
\text { NHANES entre os } \\
\text { anos de } 1999 \text { e } 2004 \\
\text { - sexo: } 46,5 \% \\
\text { masculino e } 53,5 \% \\
\text { feminino } \\
\text { - idade: entre } 18 \text { e } 65 \\
\text { anos (média=37 anos) }\end{array}$ & $\begin{array}{l}\text { - } 27 \% \text { de IA; } \\
\text { - indivíduos com IA têm } 21 \% \text { a mais de risco de } \\
\text { hipertensão do que indivíduos com SA ( } p=0,02) \text {; } \\
\text { - a associação entre a IA e evidência clínica de } \\
\text { hiperlipidemia não foi significativa }(p=0,4) \text {; } \\
\text { - o risco de diabetes clínicos foi aproximadamente } \\
50 \% \text { maior entre os adultos com IA do que aqueles } \\
\text { com SA ( } p=0,03 \text { ); } \\
\text { - entre os adultos com diagnostico da doença, a IA } \\
\text { foi associada com controle inadequado do diabetes, } \\
\text { mas não a hipertensão ou hiperlipidemia; } \\
\text { - o controle do IMC não atenuou a associação entre } \\
\text { IA e doenças crônicas, o que sugere que esta } \\
\text { associação não pode ser totalmente atribuída a um } \\
\text { aumento da prevalência de obesidade entre as } \\
\text { mulheres em situação de IA. No entanto, hipóteses } \\
\text { para explicar a associação entre IA e obesidade } \\
\text { entre as mulheres também pode explicar as } \\
\text { associaçães entre IA e as doenças crônicas } \\
\text { sensíveis à dieta. }\end{array}$ \\
\hline
\end{tabular}


Quadro 1. Estudos sobre IA e DCNT conduzidos em diversos países (conclusão).

\begin{tabular}{|c|c|c|c|c|}
\hline Referência & Local & Objetivo do estudo & População-alvo & Resultados \\
\hline Holben $^{35}$ & $\begin{array}{l}\text { Estados Unidos da } \\
\text { América (Atenas, } \\
\text { Hocking, Meigs, Perry, } \\
\text { Pike e Vinton } \\
\text { municípios de Ohio) }\end{array}$ & $\begin{array}{l}\text { Avaliar a relação da } \\
\text { segurança alimentar com } \\
\text { parâmetros clínicos de } \\
\text { vários fatores de risco para } \\
\text { doenças crônicas dos } \\
\text { moradores de seis } \\
\text { municípios rurais de Ohio. }\end{array}$ & $\begin{array}{l}\text { amostra: } \\
\text { adultos } \\
\text { - sexo: } 3580,9 \% \\
\text { masculino } \\
66,1 \% \text { feminino } \\
\text { - idade: média }=44,7 \\
\text { anos, sendo } 42,5 \% \\
\text { com <40 anos, } 33,4 \% \\
\text { entre } 40-59 \text { anos, } \\
23,1 \% \text { com }>60 \text { anos e } \\
1 \% \text { falta de dados. }\end{array}$ & $\begin{array}{l}\text { - } 27,2 \% \text { de IA; } \\
\text { - pressão arterial diastólica, colesterol total, } \\
\text { glicemia, HbA1c e hemoglobina não apresentaram } \\
\text { diferença significativa entre os status de segurança } \\
\text { alimentar ( } p>0,05 \text { para todos os parâmetros } \\
\text { clínicos); } \\
\text { - o IMC foi maior entre os indivíduos de domicílios } \\
\text { com IA, especialmente entre as mulheres ( } p=0,04) \text {, } \\
\text { quando comparados com indivíduos de domicílios } \\
\text { com SA. } \\
\text { - a obesidade foi maior entre indivíduos de } \\
\text { domicílios com IA }(48,1 \%) \text { do que entre aqueles de } \\
\text { famílias com } S A(35,1 \%, p<0,001) \text {. }\end{array}$ \\
\hline
\end{tabular}


Referências

1. Fieldhouse $P$, Thompson $S$. Tackling food security issues in indigenous communities in Canada: The Manitoba experience. Nutr Diet.2012; 69: 217-21.

2. Brasil. Ministério do Desenvolvimento Social e Combate à Fome, Secretaria Nacional de Segurança Alimentar e Nutricional, Secretaria-Executiva da Câmara Interministerial de Segurança Alimentar e Nutricional (CAISAN). Balanço traz avanços do Brasil nas ações de segurança alimentar e nutricional. Brasília: CAISAN; 2014.

3. Robaina KA, Martin KS. Food Insecurity, Poor Diet Quality, and Obesity among Food Pantry Participants in Hartford, CT. J nutr educ behav. 2013; 45: 159-64.

4. Brasil. Instituto Brasileiro de Geografia e Estatística; Ministério do Desenvolvimento Social e Combate à Fome; Ministério do Planejamento, Orçamento e Gestão. Pesquisa Nacional por Amostra de Domicílio: segurança alimentar 2004/2009. Rio de Janeiro: IBGE; 2010.

5. Pereira SMPD, Palácio MAV, Gomes Júnior JE, Santos WS. Segurança alimentar e nutricional: conhecimento e ações dos enfermeiros do programa saúde da família aos portadores de doenças crônicas. Rev bras promoçsaúde2009; 22(3): 194-8.

6. Tanumihardjo SA, Anderson C, Kaufer-Horwitz M, Bode L, Emenaker NJ, Haqq $A M$, et al. Poverty, obesity, and malnutrition: an international perspective recognizing the paradox. J Am Diet Assoc. 2007; 107: 1966-72.

7. Mohamadpour M, Sharif ZM, Keysami MA. Food insecurity, health and nutritional status among sample of palm-plantation households in Malaysia. J Health Popul Nutr. 2012; 30(3): 291-302.

8. López ABS, Seligman HK. Clinical management of food-insecure individuals with diabetes. Diabetes Spectr. 2012; 25(1): 14-8. 
9. Green-LaPierre RJ, Williams PL, Glanville NT, Norris D, Hunter HC, Watt CG. Learning from "knocks in life": food insecurity among low-income lone senior women. J Aging Res. 2012; 2012: 1-11.

10. Mark S, Lambert M, O'Loughlin J, Gray-Donald K. Household income, food insecurity and nutrition in Canadian Youth. Can J Public Health. 2012; 103(2): 94-99.

11. Ramsey R, Giskes K, Turrell G, Gallegos D. Food insecurity among adults residing in disadvantaged urban areas: potential health and dietary consequences. Public Health Nutr. 2011; 15(2): 227-37.

12. Seligman HK, Schillinger D.Hunger and Socioeconomic Disparities in Chronic Disease. N Engl J Med. 2010; 363(1): 6-9.

13. Foley W, Ward P, Carter P, Coveney J, Tsourtos G, Taylor A. An ecological analysis of factors associated with food insecurity in South Australia, 2002-7. Public Health Nutr.2009; 13(2): 215-21.

14. Chilton M, Booth $S$. Hunger of the body and hunger of the mind: African american women's perceptions of food insecurity, health and violence. J NutrEducBehav.2007; 39: 116-25.

15. Peterman JN, Wilde PE, Silka L, Bermudez OI, Rogers BL. Food insecurity among cambodian refugee women two decades post resettlement. J Immigr Minor Health.2013; 15: 372-80.

16. Dubois L, Farmer A, Girard M, Porcherie M. Family food insufficiency is related to overweight among preschoolers. Soc Sci Med. 2006; 63: 1503-16.

17. Keller HH, Dwyer JJM, Edwards V, Senson C, Edward HG. Food security in older adults: community service provider perceptions of their roles. Can J Aging. 2007; 26(4): 317-28. 
18. Kramer-LeBlanc CS, McMurry K. Discussion paper on domestic food security. Fam Econ Rev. 1998; 11(1/2):49-30.

19. Bowman S. Low economic status is associated with suboptimal intakes of nutritious foods by adults in the National Health and Nutrition Examination Survey 1999-2002. Nutr Res. 2007; 27: 515-23.

20. Kirkpatrick SI, Tarasuk V. Assessing the relevance of neighborhood characteristics to the household food security of low-income Toronto families. Public Health Nutr.2010; 13(7): 1139-48.

21. Jernigan VBB, Salvatore AL, Styne DM, Winkleby M. Addressing food insecurity in a native american reservation using community-based participatory research. Health Educ Res. 2012; 27(4): 645-55.

22. Kuyper EM, Espinosa-Hall G, Lamp CL, Martin AC, Metz DL, Smith D, et al. Development of a Tool to Assess Past Food Insecurity of Immigrant Latino Mothers.JNutrEducBehav.2006; 38: 378-82.

23. Gooze RA, Hughes CC, Finkelstein DM, Whitaker RC. Obesity and Food Insecurity at the Same Table: How Head Start Programs Respond. Prev Chronic Dis. 2012; 9: 1-8.

24. Gundersen C, Kreider B, Pepper J. The Economics of Food Insecurity in the United States. Applied Economic Perspectives and Policy 2011; 33(3): 281-303.

25. Friel S. Climate change, food insecurity and chronic diseases: sustainable and healthy policy opportunities for Australia. N S W Public Health Bull. 2010; 21(5-6): 129-133.

26. Jiménez-Cruz A, Bacardí-Gascón M, Spindler AA. Obesity and hunger among Mexican-Indian migrant children on the US-Mexico border. Int J Obes. 2003; 27: 74047. 
27. Sharkey JR, Nalty C, Johnson CM, Dean WR. Children's very low food security is associated with increased dietary intakes in energy, fat, and added sugar among Mexican-origin children(6-11 y) in Texas border Colonias. BMC Pediatr.2012; 16: 112.

28. Belachew T, Lindstrom D, Gebremariam A, Jira C, Hattori MK, Lachat C, et al. Predictors of chronic food insecurity among adolescents in Southwest Ethiopia: a longitudinal study. BMC Public Health.2012; 12: 604-16.

29. Kaiser LL, Melgar-Quiñonez H, Townsend MS, Nicholson Y, Fujii ML, Martin AC, et al. Food insecurity and food supplies in latino households with young children. $J$ NutrEducBehav.2003; 35:148-153.

30. Champagne CM, Casey PH, Connell CL, Stuff JE, Gossett JM, Harsha DW, et al. Poverty and food intake in rural America: diet quality is lower in food insecure adults in the Mississippi Delta. J Am Diet Assoc. 2007; 107:1886-94.

31. Cheng S, Kamano J, Kirui NK, Manuthu E, Buckwalter V, Ouma K, Pastakia SD, et al. Prevalence of food insecurity in patients with diabetes in western Kenya. Diabet Med. 2013; 30: 215-22.

32. Lyles CR, Wolf MS, Schillinger D, Davis TC, DeWalt D, Dahlke AR, et al. Food insecurity in relation to changes in hemoglobin A1c, self-efficacy, and fruit/vegetable intake during a diabetes education intervention. Diabetes Care.2013; 36: 1448-53.

33. Billimek J, Sorkin DH. Food insecurity, processes of care, and self-reported medication underuse in patients with type 2 diabetes: results from the California Health Interview Survey. Health Serv Res.2012; 47(6): 2159-68.

34. Seligman HK, Laraia BA, Kushel MB. Food Insecurity Is Associated with Chronic Disease among Low-Income NHANES Participants. J Nutr.2010; 140: 304-10.

35. Holben DH, Pheley AM. Diabetes risk and obesity in food-insecure households in rural Appalachian Ohio. Prev Chronic Dis. 2006; 3(3): 1-9. 


\subsection{ARTIGO 2 - "ASSOCIAÇÃO ENTRE FATORES DE RISCO E OCORRÊNCIA DE DOENÇAS CRÔNICAS COM INSEGURANÇA ALIMENTAR GRAVE NO DISTRITO FEDERAL"}

Submetido à revista Cadernos de Saúde Pública

Ana Lilian Bispo dos Santos, Muriel Bauermann Gubert, Andressa Cristina Santos de Deus

\section{RESUMO}

Foi realizado um estudo transversal com a população adulta do Distrito Federal (DF), no período de fevereiro a junho de 2014, para pesquisar a associação entre fatores de risco e ocorrência de doenças crônicas não transmissíveis (DCNT) com a insegurança alimentar grave (IAG) no DF. Os dados foram coletados por meio de entrevista, a partir de questionário com perguntas fechadas.A amostra representativa da população do DF foi composta por 324 adultos, dos quais $74,1 \%$ tinham SA e 25,9\% IAG. Os resultados apontam uma tendência de associação positiva da IAG com doença cardiovascular - DCV (OR:1,79), consumo de carnes com excesso de gordura (OR:2,11) e obesidade (OR:2,11). Essa associação passa a ser negativa para as variáveis prática de atividade física (OR:0,45), consumo de feijão (OR:0,47), frutas $(\mathrm{OR}: 0,19)$ e hortaliças $(\mathrm{OR}: 0,44)$. Este estudo evidencia a existência da tendência de associação da IAG com DCV, e sugere uma possível associação com diabetes e câncer. Há também uma relação entre IAG e fatores de risco para DCNT, relacionados ao consumo alimentar inadequado e sedentarismo.

Palavras-chave: doença crônica; segurança alimentar e nutricional; alimentação; fome. 


\begin{abstract}
A cross-sectional study of the adult population of the Distrito Federal (DF) was carried out from February to June 2014 in order to investigate the association between risk factors and the occurrence of chronic diseases (CD) with severe food insecurity (SFI) in DF. Data were collected through interviews, by a questionnaire with closed questions. A representative sample of the DF's population consisted of 324 adults in which $74.1 \%$ had SA and $25.9 \%$ SFI. The results show a positive trend of SFI association with cardiovascular disease - CVD (OR: 1.79), meat consumption with fat excess (OR: 2.11) and obesity (OR: 2.11). This association becomes negative for the variables practice of physical activity (OR: 0.45), consumption of beans (OR:0.47), fruit (OR: 0.19) and vegetables (OR: 0.44). This study shows the existence of the association trend of SFI with CVD, and suggests a possible association with diabetes and cancer. There is also a relationship between SFI and risk factors for $C D$, related to inadequate dietary intake and physical inactivity.
\end{abstract}

Key words: chronic disease; food security; feeding; hunger. 
Introdução

A insegurança alimentar (IA) consiste na incapacidade de acesso regular e permanente a alimentos de qualidade, em quantidade suficiente, sem comprometer o acesso a outras necessidades essenciais, tendo como base práticas alimentares promotoras de saúde que respeitem a diversidade cultural e que sejam ambiental, cultural, econômica e socialmente sustentáveis ${ }^{1}$. Em 2013, foi estimada a magnitude da IA em 22,6\% de domicílios particulares brasileiros, sendo que neles viviam cerca de 52 milhões de pessoas ${ }^{2}$. Estes resultados são elevados quando comparados aos dados norte americanos de 2010, onde 14,5\% dos domicílios apresentavam IA ${ }^{3,4}$, porém semelhantes a países africanos como a República do Quênia ${ }^{5}$. Estudos realizados em países desenvolvidos apontam que a IA pode chegar a até $82 \%$ de prevalência entre grupos desfavorecidos, tais como as minorias étnicas e as famílias monoparentais ${ }^{6}$.

Os efeitos da IA podem resultar em encargos significativos para a saúde pública. Ela está relacionada à diminuição do consumo de alguns grupos de alimentos (frutas e hortaliças, cereais integrais, carnes, produtos lácteos) ${ }^{7}$, bem como redução na variedade e no tamanho das porções dos alimentos, desencadeando inadequação da ingestão de nutrientes, com consequente impacto na redução do estado geral de saúde e aumento do número de visitas ao médico ou hospital ${ }^{6}$. Tal fato resulta em carências nutricionais e até mesmo obesidade, nas populações inseguras ${ }^{7}$.

É sabido que a desnutrição pregressa, ocorrida durante a gestação e infância do indivíduo, é fator de risco para doenças crônicas não transmissíveis (DCNT) ${ }^{8}$. Há indícios, porém, que IA atual também pode apresentar relação causal com doenças crônicas $^{9}$. A hipótese seria de que a IA pode resultar no aumento do consumo de energia barata proveniente de alimentos com alta densidade calórica e na omissão de refeições, com longos períodos de jejum, muitas vezes seguidos de períodos de ingestão compulsiva de alimentos. Esse mecanismo aconteceria durante tempo suficiente para alterar o metabolismo e resultar em um balanço energético positivo, originando obesidade, que é fator de risco para o desenvolvimento de outras doenças crônicas relacionadas à dieta inadequada ${ }^{6,7,9}$.

Hábitos relacionados à dieta como consumo insuficiente de frutas e hortaliças e consumo excessivo de açúcares simples e de gordura saturada têm sido 
considerados importantes fatores de risco para DCNT e estão incluídos tanto nas recomendações do novo guia alimentar da população brasileira, como no sistema de Vigilância de Fatores de Risco e Proteção para Doenças Crônicas por Inquérito Telefônico - VIGITEL ${ }^{1,7,10-12}$.

De acordo com o Relatório Mundial sobre as DCNT de 2010, as dietas inadequadas, o sedentarismo, o uso nocivo de bebida alcoólica e o tabagismo, são considerados comportamentos de risco para o desenvolvimento de DCNT e precisam ser combatidos ${ }^{7,13,14}$.

As DCNT são a principal fonte da carga de doenças no Brasil e foram responsáveis por $72 \%$ das mortes ocorridas em 2007 , tendo se tornado prioridade do governo na área da saúde ${ }^{13-15}$. Cabe ressaltar que o crescimento da renda, a industrialização e mecanização da produção, a urbanização, o maior acesso a alimentos em geral (incluindo os processados) e a globalização de hábitos não saudáveis produziram rápida transição nutricional no país, expondo a população cada vez mais ao risco de doenças crônicas ${ }^{13,14}$. Nesse contexto, grupos étnicos e sociais menos privilegiados tem grande participação na carga resultante dessas doenças, chegando a ser desproporcional ao que representam na população brasileira como um todo ${ }^{7,14,16}$. Esses grupos menos privilegiados são os mesmos que tem maior participação nas taxas de IA no país ${ }^{17}$.

A relação entre IA e DCNT tem sido estudada em algumas populações do mundo. Estudo realizado na Austrália evidenciou associação entre IA e menor renda familiar, pior estado geral de saúde, maior utilização de cuidados de saúde e depressão ${ }^{6}$. Nos Estados Unidos foi evidenciado maior prevalência de hiperlipidemia, hipertensão e diabetes entre indivíduos com IA quando comparados aos indivíduos que apresentavam segurança alimentar $(\mathrm{SA})^{3}$. Segundo Gowda ${ }^{18}$, a IA esteve associada à inflamação celular, um correlato de doenças crônicas, em estudo realizado com a população norte americana. No Canadá, a transição nutricional e IA estão associadas a uma mudança multifacetada no status de nutrientes, com implicações para o aumento do risco de doenças crônicas sensíveis a dieta $^{19}$. Na Jordânia, estudo conduzido por Bawadi ${ }^{20}$ identificou que a IA pode estar associada com danos ao controle glicêmico em pacientes com diabetes tipo 2.

Entretanto, no Brasil ainda são escassos os estudos deste tipo. Existem alguns estudos utilizando dados de pesquisas nacionais, numa abordagem de ciclos de vida, para analisar a obesidade entre as mulheres, adolescentes do sexo 
feminino e crianças brasileiras afetadas por diferentes graus de $\mathrm{IA}^{21-24}$, que evidenciaram uma associação entre IA e obesidade em mulheres e adolescentes do sexo feminino, mas não em crianças. Santos $^{25}$ pondera que ainda não há uma resposta definitiva sobre a relação fome e obesidade no Brasil. Provavelmente, a fome leva à obesidade entre mulheres, mas em homens, pela escassez de dados, não foi possível estudar-se essa relação.

No Brasil a IA tem sido associada à obesidade, porém ainda são obscuros os aspectos relacionados à população masculina e sua associação com outras DCNT. Pesquisar os aspectos relacionados a este fenômeno torna-se importante tanto para o planejamento de futuras estratégias de intervenções nutricionais quanto para a formulação de políticas públicas, que garantam as condições de segurança alimentar e manutenção do estado de saúde da população. Dessa forma, o objetivo deste estudo foi pesquisar a associação entre fatores de risco e ocorrência de DCNT com IA grave (IAG) no Distrito Federal (DF).

Métodos

Trata-se de um estudo transversal, realizado com a população adulta do DF, no período de fevereiro a junho de 2014.

A amostra foi aleatória, estratificada por faixa de renda domiciliar per capita e situação de segurança alimentar (SA), representativa por cota para a população do DF em situação de SA e IA grave (IAG). O tamanho estimado da amostra foi de 324 indivíduos, 240 em situação de SA e 84 em IAG, com erro máximo amostral de 10\% e nível de confiança igual a $95 \%$.

A amostragem foi do tipo sistemática e estratificada por renda, sendo a seleção dos entrevistados realizada nas rodoviárias do Distrito Federal, em virtude do grande fluxo de pessoas, a fim de diminuir o viés amostral. Foram adotados os seguintes critérios de inclusão: ter idade igual ou superior a 18 anos, residir no DF, ter conhecimento sobre a disponibilidade de alimentos no domicílio, estar em situação de SA ou IAG. Mulheres grávidas, pessoas com incapacidade cognitiva, surdos e mudos foram excluídos da amostra.

Os dados foram coletados por meio da aplicação de questionário com perguntas fechadas composto por perguntas oriundas do Vigitel - Vigilância de 
Fatores de Risco e Proteção para Doenças Crônicas por Inquérito Telefônico ${ }^{11}$ e pela Escala Brasileira de Insegurança Alimentar².

O questionário abordava os seguintes aspectos: a) características demográficas e socioeconômicas; b) padrão alimentar e atividade física (associadas à ocorrência de DCNT); c) peso e altura referidos; d) frequência do consumo de bebidas alcoólicas; e) referência a diagnóstico médico anterior de DCNT (doença cardiovascular, diabetes e câncer); e f) situação de segurança alimentar.

Para verificar a ocorrência de DCNT, utilizou-se a variável de diagnóstico médico prévio de diabetes, doença cardiovascular (insuficiências cardíacas congestivas, acidente vascular cerebral, infarto agudo do miocárdio, arritmias cardíacas, isquemias, anginas, hipertensão arterial sistêmica) e câncer.

$\mathrm{Na}$ identificação da ocorrência de fatores de risco para DCNT, utilizou-se a prevalência de adultos com excesso de peso (índice de massa corporal $\geq 25 \mathrm{~kg} / \mathrm{m}^{2}$ ) e obesidade (índice de massa corporal $\geq 30 \mathrm{~kg} / \mathrm{m}^{2}$ ); consumo de alimentos considerados marcadores de padrões saudáveis: feijão $(\geq 1 x /$ dia), fruta $(\geq 3 x /$ dia) e hortaliça ( $\geq 3 x /$ dia), e não saudáveis: carnes com excesso de gordura, leite com teor integral de gordura e refrigerante normal; prática recomendada de atividade física no tempo livre ( $\geq 150 \mathrm{~min} . /$ semana); consumo abusivo de bebidas alcoólicas ( $q$ : $>$ 4doses/ocasião e $\sigma^{\lambda}$ : >5doses/ocasião).

Embora a obesidade seja um tipo de doença crônica, neste estudo ela foi considerada fator de risco para o desenvolvimento de outras DCNT relacionadas à dieta inadequada ${ }^{2,3,6,7}$.

Para mensuração da situação de segurança alimentar foi utilizada a prevalência de domicílios classificados como seguros e inseguros grave.

Um escore de alimentação saudável foi elaborado para avaliar as questões de consumo alimentar, incluindo as variáveis: feijão, frutas, verduras cruas, legumes cozidos, leite e refrigerante, em quatro níveis de frequência de consumo semanal. $O$ escore foi calculado a partir da soma da pontuação dos itens, podendo variar de 0 a $24^{12}$.

As variáveis foram analisadas no programa SPSS Statistics versão 20. A descrição da amostra foi realizada por meio de análise univariada. As estimativas fornecidas pela análise bivariada de variáveis categóricas foram expressas por prevalências e intervalos de confiança de 95\%, sendo utilizado teste do quiquadrado para comparação entre as variáveis categóricas. A análise ajustada foi 
realizada por meio de regressão logística e expressa em odds ratio $(\mathrm{OR})$, sendo as variáveis consideradas no modelo para o ajuste biológico: sexo, idade e raça; e o ajuste social: escolaridade e renda. Para comparação das médias dos escores de alimentação saudável foi utilizado o teste t-student. O nível de significância considerado foi de $5 \%$.

Esta pesquisa foi aprovada pelo Comitê de Ética em Pesquisa da Universidade de Brasília sob o protocolo n 18340813.8.0000.0030.

Resultados

A amostra final foi composta por 324 adultos moradores do DF, dos quais $74,1 \%$ em situação de SA e 25,9\% em situação de IAG. A idade média foi de $39,1 \pm 15,9$ anos. Dos entrevistados, $53,7 \%$ eram do sexo feminino.

A DCNT mais prevalente foi doença cardiovascular $(21,9 \%)$, seguida de diabetes $(9,0 \%)$ e câncer $(3,4 \%)$.

Indivíduos com IAG apresentaram maior prevalência de doença cardiovascular (DCV), obesidade e consumo de pele de frango quando comparados aos seguros $(p<0,05)$. Por outro lado, indivíduos com SA apresentaram maior prevalência de prática de atividade física, consumo de feijão, frutas e hortaliças $(p<0,05)$.

Foram observados maiores níveis de escolaridade e renda em pessoas com SA $(p<0,05)$ (Tabela 1).

Ao verificar a associação entre IAG e DCNT, foi possível observar que indivíduos inseguros têm 79\% mais chances de apresentar DCV do que os seguros, quando as variáveis biológicas e sociais não são ajustadas. Porém quando essas variáveis são controladas no modelo, a associação deixa de ser significativa (Tabela 2).

$\mathrm{Na}$ avaliação do consumo alimentar, a média do escore de alimentação

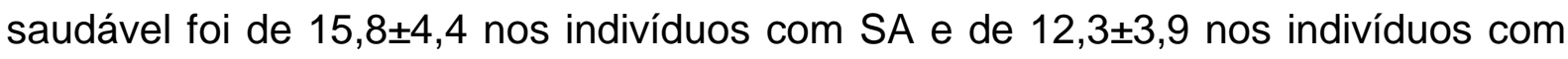
IAG. Na comparação entre as médias o valor de t-student foi igual a 6,84 ( $p=0,00)$.

Houve associação entre IAG e consumo de feijão, frutas, hortaliças e pele de frango. Indivíduos inseguros têm menos chances de consumir a recomendação de feijão (OR: 0,47; IC 95\%: 0,28 - 0,79), frutas (OR: 0,19; IC 95\%: 0,04 - 0,79) e 
hortaliças (OR: 0,44; IC 95\%: 0,22 - 0,89) e chance 2,11 vezes maior de consumir pele de frango do que os seguros, mesmo quando as variáveis biológicas e sociais são controladas (Tabela 3). Inseguros tendem a consumir $83 \%$ mais carne vermelha com gordura do que os seguros, permanecendo a associação quando o modelo é ajustado pelas variáveis sociais.

Conforme visualizado na Tabela 4, indivíduos inseguros graves apresentam 2,21 vezes mais chances de ser obeso do que os seguros quando as variáveis biológicas e sociais não são ajustadas. Em relação à atividade física, observa-se que pessoas em situação de IAG praticam menos atividade física do que as seguras (OR: 0,45; IC 95\%: 0,24 - 0,82).

\section{Discussão}

Os resultados deste trabalho apontam uma tendência de associação positiva da IAG com DCNT (DCV, diabetes e câncer), consumo de carnes com excesso de gordura e obesidade. Essa associação passa a ser negativa para as variáveis relacionadas a comportamento protetor contra DCNT, como a prática de atividade física, consumo de feijão, frutas e hortaliças.

$\mathrm{Na}$ comparação entre os grupos de indivíduos em situação de SA e IAG foram observados maiores níveis de escolaridade e renda em pessoas com SA, o que caracteriza maior vulnerabilidade econômica dos inseguros, fator este associado com o consumo alimentar. Essa limitação econômica pode estar relacionada a uma dieta mais barata e nutricionalmente mais pobre, com maior consumo de alimentos com alta densidade calórica e baixo valor nutricional, como os industrializados, ricos em açúcar, sódio e gordura trans. Bem como a um menor consumo de alimentos saudáveis, como frutas, verduras e legumes, ricos em vitaminas, minerais e fibras ${ }^{26-}$ 28 .

Segundo Sartori ${ }^{27}$ e Cotta $^{28}$, essa realidade está presente também entre beneficiários do Programa Bolsa Família, um programa de transferência direta de renda com condicionalidades, destinado às famílias de baixa renda. Embora se tenha percebido uma relação significativa entre a elevação da renda familiar e a melhora dos níveis de $1 \mathrm{~A}^{29}$, o maior poder de compra dos participantes do programa também aumentou o consumo de alimentos não saudáveis ${ }^{12,29-31}$. Esses achados 
sugerem que o consumo alimentar inadequado de indivíduos em situação de IA não está relacionado apenas à limitação econômica, mas também ao acesso e compreensão das informações em saúde. Ressalta-se a necessidade de se repensar o referido programa, pois ele conseguiu impactar na redução da IA, mas possivelmente aumenta a exposição a fatores de risco para doenças crônicas.

Observou-se que indivíduos inseguros têm mais chances de apresentar DCV comparados aos seguros. Embora essa associação perca força quando as variáveis biológicas e sociais são ajustadas no modelo, a tendência se mantém. Essa tendência de associação aparece inclusive para as outras DCNT, como diabetes e câncer, embora não significativa. Estudos apontam a possibilidade de existência de associação da IA na predisposição e no controle das DCNT devido a adaptações dietéticas inadequadas desencadeadas pela IA como por exemplo a adoção de estratégias compensatórias durante a adequação alimentar e a escassez de alimentos, podendo levar a um quadro de obesidade, hipertensão e diabetes. Uma vez instalada a DCNT, este quadro prejudica a capacidade de autogestão da doença, além de gerar demandas conflitantes, que por sua vez aumentam a vulnerabilidade econômica, mental, física e social, fechando um ciclo vicioso de relação entre a IAG e a $D C N T^{6,14,32,33}$.

De acordo com o relatório de Enfrentamento das Doenças Não Transmissíveis no Brasil elaborado pelo Banco Mundial em $2005^{26}$, os pobres no Brasil sofrem uma dupla carga de doenças. Eles são mais afetados pelas doenças infectocontagiosas, assim como pelas não transmissíveis. Essa dupla carga onera ainda mais o ciclo da pobreza. As DCNT são algumas vezes chamadas, de forma equivocada, de "doenças de riqueza" devido ao fato de estarem associadas à urbanização e à modernização. No entanto, a associação entre DCNT e pobreza é forte. Em alguns casos, isso se deve ao fato dos pobres apresentarem maiores fatores de risco. Em outros casos à incapacidade causada pela própria doença não transmissível. As taxas de mortalidade são mais altas nesta população porque os pobres têm menores chances de fazer um diagnóstico precoce e um tratamento apropriado. A progressão da doença pode ser bem mais rápida, e o fato de lidar com ela pode colocar a família em uma situação de pobreza ainda maior. Sendo assim, ligações entre pobreza e DCNT devem ser consideradas na formulação de políticas $^{26}$. 
Gowda, Hadley e Aiello ${ }^{34}$ conseguiram evidências da presença dessa dupla carga de doenças na população norte americana em situação de IA por meio da identificação do papel de biomarcadores do sistema imunológico no caminho entre IA e inflamação, um correlato importante de várias doenças crônicas. Segundo os autores, a IA está associada a níveis plasmáticos elevados da proteína C-reativa (PCR), um biomarcador validado da inflamação, sugerindo que a inflamação pode ser um mecanismo pelo qual a IA predispõe ao aparecimento da doença crônica, como diabetes, hipertensão e doença cardiovascular ${ }^{34-36}$. Este mesmo estudo também indicou que inseguros são mais propensos a apresentar baixo nível de ácido fólico, nutriente envolvido na ativação do sistema imune, o que os torna mais suscetíveis a doenças infecciosas, além de $40 \%$ mais chances de terem contagem de glóbulos brancos elevada, um indicador de infecção.

Analisando-se o padrão alimentar dos grupos de seguros e inseguros graves, observou-se que indivíduos inseguros graves apresentaram menores chances de consumir a recomendação de marcadores alimentares saudáveis, como feijão, frutas e hortaliças e maiores chances de consumir alimentos considerados marcadores não saudáveis, como carne com excesso de gordura, do que os seguros, mesmo quando as variáveis biológicas e sociais são controladas.

Sabe-se que a IA, caracterizada pelo acesso limitado ou incerto ou ainda insuficiente a alimentos seguros e nutricionalmente adequados, pode resultar no aumento do consumo de energia barata proveniente de alimentos com alta densidade calórica, acarretando consumo insuficiente de frutas e hortaliças, bem como consumo excessivo de açúcares simples e gordura saturada ${ }^{6,32,33,37-42}$.

Existe a possibilidade de que a IAG tenha participação no agravamento do hábito alimentar inadequado da população do DF. Ao comparar dados do Vigitel Brasil 2013 sobre o padrão alimentar da população do DF com dados da população de inseguros deste estudo, observa-se que os percentuais de consumo regular de frutas e hortaliças, bem como do consumo de carnes com excesso de gordura, na população do $D F$, foram de $40 \%$ e $33,4 \%$, respectivamente ${ }^{11}$. Enquanto na presente pesquisa, onde se trabalhou com uma amostra representativa para a população insegura do DF, os percentuais de consumo foram de 2,4\% (frutas), $13,1 \%$ (hortaliças), 39,3\% (gordura da carne vermelha) e 35,7\% (pele de frango). Isso aponta para um pior padrão alimentar em situação de insegurança alimentar, estando esta população em maior vulnerabilidade para as DCNT. 
A associação da IAG com obesidade foi estatisticamente significativa, quando não houve controle das variáveis biológicas e sociais, indicando mais chances de obesidade entre os inseguros quando comparados aos seguros. Sabe-se que, na situação de IA, há aumento do consumo de energia barata proveniente de alimentos com alta densidade calórica e omissão de refeições, com longos períodos de jejum, muitas vezes seguidos de períodos de ingestão compulsiva desses alimentos. Tal mecanismo acontece durante tempo suficiente para alterar o metabolismo e resultar em um balanço energético positivo, originando obesidade ${ }^{6,7,9}$. Além disso, a inatividade física, que neste estudo foi mais presente em indivíduos inseguros, também contribui para o desenvolvimento da obesidade. $O$ sedentarismo dobra 0 risco de obesidade ${ }^{26}$.

Outra possível explicação para a maior presença de obesidade entre os inseguros graves é a hipótese de que situações de privação, tanto quantitativa quanto qualitativa, ao acesso a alimentos ainda na infância, estão associadas ao desencadeamento da obesidade em adultos ${ }^{43}$. Como a interrupção do ciclo de pobreza intergeracional é difícil ${ }^{44}$, muitos dos inseguros atualmente poderiam ter sido crianças inseguras. Essa hipótese pode, inclusive, elucidar a possível relação da IA atual com DCNT.

Foi observado que pessoas em situação de IAG praticam menos atividade física do que as seguras. No entanto, esta associação deixa de ser significativa quando as variáveis sociais são controladas no modelo. Apesar disso, ressalta-se a importância desse achado, pois a atividade física reduzida torna os indivíduos inseguros vulneráveis ao desenvolvimento de DCNT e suas complicações. Vepsalainen ${ }^{36}$ sugere uma ação anti-inflamatória da atividade física na prevenção da morbidade e mortalidade de doenças cardiovasculares e coronarianas associadas com níveis elevados de PCR.

A pobreza, presente na maioria dos casos de IAG, pode contribuir para exclusão social da prática de atividade física. As alternativas de exercícios são reduzidas em locais de habitações populares construídas de forma precária e desprovidas de infraestrutura, como as favelas, que possuem poucas áreas verdes e parques necessários para a promoção da prática de atividade física. Esses locais costumam ser violentos, o que pode fazer com que as escolhas de exercícios sejam reduzidas por medo da exposição à violência ${ }^{26}$. 
No Brasil, a frequência de adultos que praticam atividades físicas no tempo livre, equivalentes a pelo menos 150 minutos por semana, varia entre $28,0 \%$ em São Luís e $43,9 \%$ em Florianópolis ${ }^{11}$. Nesta pesquisa, essa frequência foi de $19 \%$ entre os inseguros e de $34 \%$ entre os seguros.

Hábitos inadequados relacionados à dieta têm sido considerados importantes fatores de risco para DCNT, principal fonte da carga de doenças no Brasil, e estão incluídos tanto nas recomendações de alimentação saudável, como no VIGITEL ${ }^{10-12}$. A Organização Mundial da Saúde considera o sedentarismo comportamento de risco para o desenvolvimento de $\mathrm{DCNT}^{7}$. Nesta pesquisa, todos esses fatores considerados de risco estiveram associados à IAG. Sendo assim, para combater as DCNT faz-se necessário empenho em traçar estratégias para redução da situação de IAG, por meio do adequado financiamento e aumento da utilização de programas de assistência alimentar e nutricional, da inclusão da educação alimentar e nutricional em todos os programas que fornecem alimentos e assistência nutricional, bem como programas de promoção da autossuficiência econômica dos indivíduos e das famílias.

Conclusão

Este trabalho evidencia a existência da tendência de associação da IAG com DCV, e sugere uma possível associação com diabetes e câncer, o que não pôde ser comprovado. Há também uma relação entre IAG e fatores de risco para DCNT, relacionados ao consumo alimentar inadequado e sedentarismo.

Considerando-se que grupos menos privilegiados têm grande participação nas taxas de DCNT e IAG, é de fundamental importância entender a associação entre essas taxas para auxiliar no planejamento de políticas públicas mais eficientes para manutenção das condições de saúde e segurança alimentar desses indivíduos. 
Tabela 1. Características demográficas, de saúde, consumo alimentar e situação de segurança alimentar da

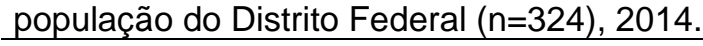

\begin{tabular}{|c|c|c|c|c|c|}
\hline & \multicolumn{2}{|c|}{ SA $(n=240)$} & \multicolumn{2}{|c|}{ IAG (n=84) } & \multirow{2}{*}{ Valor $p$} \\
\hline & $\%$ & IC $95 \%$ & $\%$ & IC 95\% & \\
\hline $\begin{array}{l}\text { Sexo } \\
\text { feminino } \\
\text { masculino }\end{array}$ & $\begin{array}{l}50,8 \\
49,2\end{array}$ & $\begin{array}{l}(44,5-57,2) \\
(42,8-55,5)\end{array}$ & $\begin{array}{l}61,9 \\
38,1\end{array}$ & $\begin{array}{l}(51,5-72,3) \\
(27,7-48,5)\end{array}$ & 0,080 \\
\hline $\begin{array}{l}\text { Idade } \\
18 \text { a } 29 \text { anos } \\
30 \text { a } 39 \text { anos } \\
40 \text { a } 49 \text { anos } \\
50 \text { a } 59 \text { anos } \\
\geq 60 \text { anos }\end{array}$ & $\begin{array}{l}38,3 \\
17,5 \\
18,8 \\
12,1 \\
13,3\end{array}$ & $\begin{array}{l}(32,2-44,5) \\
(12,7-22,3) \\
(13,8-23,7) \\
(8,0-16,2) \\
(9,0-17,6)\end{array}$ & $\begin{array}{l}23,8 \\
22,6 \\
29,8 \\
14,3 \\
9,5\end{array}$ & $\begin{array}{l}(14,7-32,9) \\
(13,7-31,6) \\
(20,0-39,5) \\
(6,8-21,8) \\
(3,2-15,8)\end{array}$ & 0,058 \\
\hline $\begin{array}{l}\text { Raça } \\
\text { branca } \\
\text { preta/parda } \\
\text { amarela/indígena }\end{array}$ & $\begin{array}{l}24,2 \\
72,5 \\
3,3\end{array}$ & $\begin{array}{c}(18,8-29,6) \\
(66,9-78,1) \\
(1,1-5,6)\end{array}$ & $\begin{array}{l}21,4 \\
75,0 \\
3,6\end{array}$ & $\begin{array}{l}(12,7-30,2) \\
(65,7-84,3) \\
(-0,4-7,5)\end{array}$ & 0,877 \\
\hline $\begin{array}{l}\text { Escolaridade } \\
\text { ensino fundamental incompleto ou não ( } \leq 9 \text { anos) } \\
\text { ensino médio completo ou não ( }>9 \text { e } \leq 12 \text { anos) } \\
\text { ensino superior completo ou não (>12 anos) }\end{array}$ & $\begin{array}{l}24,2 \\
49,2 \\
26,6\end{array}$ & $\begin{array}{l}(18,8-29,6) \\
(42,8-55,5) \\
(21,1-32,3)\end{array}$ & $\begin{array}{l}42,9 \\
41,7 \\
15,4\end{array}$ & $\begin{array}{l}(32,3-53,4) \\
(31,1-52,2) \\
(7,7-23,2)\end{array}$ & 0,003 \\
\hline $\begin{array}{l}\text { Renda per capita } \\
\leq 1 / 4 \text { SM } \\
>1 / 4 \text { a } 1 / 2 S M \\
>1 / 2 \text { a } 1 S M \\
>1 \text { a } 2 S M \\
>2 S M\end{array}$ & $\begin{array}{l}3,3 \\
12,5 \\
25,0 \\
32,1 \\
27,1\end{array}$ & $\begin{array}{c}(1,1-5,6) \\
(8,3-16,7) \\
(19,5-30,5) \\
(26,2-38,0) \\
(21,5-32,7)\end{array}$ & $\begin{array}{l}25,0 \\
27,4 \\
27,4 \\
13,1 \\
7,1\end{array}$ & $\begin{array}{l}(15,7-34,3) \\
(17,8-36,9) \\
(17,8-36,9) \\
(5,9-20,3) \\
(1,6-12,7)\end{array}$ & 0,000 \\
\hline $\begin{array}{l}\text { Padrão alimentar } \\
\text { consumo protetor }\end{array}$ & & & & & \\
\hline $\begin{array}{l}\text { feijão } \geq 1 \times / \text { dia } \\
\text { fruta } \geq 3 x / \text { dia } \\
\text { hortaliças } \geq 3 x / \text { dia } \\
\text { consumo de risco }\end{array}$ & $\begin{array}{l}70,0 \\
11,7 \\
25,4\end{array}$ & $\begin{array}{l}(64,2-75,8) \\
(7,6-15,7) \\
(19,9-30,9)\end{array}$ & $\begin{array}{c}52,4 \\
2,4 \\
13,1\end{array}$ & $\begin{array}{l}(41,7-63,1) \\
(-0,9-5,6) \\
(5,9-20,3)\end{array}$ & $\begin{array}{l}0,003 \\
0,012 \\
0,019\end{array}$ \\
\hline $\begin{array}{l}\text { leite integral } \\
\text { refrigerante normal } \\
\text { gordura da carne vermelha } \\
\text { pele do frango }\end{array}$ & $\begin{array}{l}58,3 \\
50,0 \\
28,8 \\
20,8\end{array}$ & $\begin{array}{l}(52,1-64,6) \\
(43,7-56,3) \\
(23,0-34,5) \\
(15,7-26,0)\end{array}$ & $\begin{array}{l}54,8 \\
47,6 \\
39,3 \\
35,7\end{array}$ & $\begin{array}{l}(44,1-65,4) \\
(36,9-58,3) \\
(28,8-49,7) \\
(25,5-46,0)\end{array}$ & $\begin{array}{l}0,569 \\
0,707 \\
0,074 \\
\mathbf{0 , 0 0 6}\end{array}$ \\
\hline $\begin{array}{l}\text { Estado nutricional } \\
\text { sobrepeso }\left(I M C \geq 25 \mathrm{~kg} / \mathrm{m}^{2}\right) \\
\text { obesidade }\left(I M C \geq 30 \mathrm{~kg} / \mathrm{m}^{2}\right)\end{array}$ & $\begin{array}{l}35,8 \\
11,7\end{array}$ & $\begin{array}{l}(29,8-41,9) \\
(7,6-15,7)\end{array}$ & $\begin{array}{l}29,8 \\
22,6\end{array}$ & $\begin{array}{l}(20,0-39,5) \\
(13,7-31,6)\end{array}$ & $\begin{array}{l}0,313 \\
\mathbf{0 , 0 1 4}\end{array}$ \\
\hline $\begin{array}{l}\text { Atividade física } \\
\text { recomendado ( } \geq 150 \mathrm{~min} .)\end{array}$ & 34,6 & $(28,6-40,6)$ & 19,0 & $(10,7-27,4)$ & 0,008 \\
\hline $\begin{array}{l}\text { Consumo de bebida alcoólica } \\
\text { uso abusivo* }\end{array}$ & 27,1 & $(21,5-32,7)$ & 20,2 & $(11,6-28,8)$ & 0,214 \\
\hline $\begin{array}{l}\text { Doenças crônicas não transmissíveis } \\
\text { DCV } \\
\text { Diabetes } \\
\text { Câncer }\end{array}$ & $\begin{array}{l}19,2 \\
8,3 \\
2,5\end{array}$ & $\begin{array}{c}(14,2-24,1) \\
(4,8-11,8) \\
(0,5-4,5)\end{array}$ & $\begin{array}{c}29,8 \\
10,7 \\
6,0\end{array}$ & $\begin{array}{l}(20,0-39,5) \\
(4,1-17,3) \\
(0,9-11,0)\end{array}$ & $\begin{array}{l}\mathbf{0 , 0 4 3} \\
0,511 \\
0,133\end{array}$ \\
\hline $\begin{array}{l}\text { Frequência (\%); intervalo de } 95 \% \text { de confianç } \\
\text { doses/ocasião) e } \delta(+5 \text { doses/ocasião); do } \\
\text { acidente vascular cerebral, infarto agudo do }\end{array}$ & & rio mínimo (S & & $\mathrm{ca}=\mathrm{R} \$ 724,0$ & $\begin{array}{l}* \text { * }(+4 \\
\text { gestivas }\end{array}$ \\
\hline
\end{tabular}


Tabela 2. Prevalência bruta e odds ratios brutos e ajustados para a associação entre IAG e DCNT $\left(\mathrm{n}_{\mathrm{SA}}=240\right.$ e $\left.\mathrm{n}_{\mathrm{IAG}}=84\right)$. Distrito Federal, 2014.

\begin{tabular}{lccc}
\hline & DCV & Diabetes & Câncer \\
\hline Prev. (\%) IAG & 29,80 & 10,70 & 6,00 \\
Prev. (\%) SA & 19,20 & 8,30 & 2,50 \\
OR bruto (95\% IC) & $1,79(1,01-3,15)^{*}$ & $1,32(0,58-3,03)$ & $2,47(0,73-8,31)$ \\
OR aj. bio. (95\% IC) & $1,87(0,97-3,61)$ & $1,28(0,50-3,26)$ & $2,23(0,63-7,87)$ \\
OR aj. soc. $(95 \%$ IC) & $1,52(0,79-2,95)$ & $0,94(0,35-2,49)$ & $2,57(0,63-10,58)$ \\
\hline
\end{tabular}

DCV: doença cardiovascular (insuficiências cardíacas congestivas, acidente vascular cerebral, infarto agudo do miocárdio, arritmias cardíacas, isquemias, anginas, hipertensão arterial sistêmica);OR aj. bio.: odds ratio ajustado para sexo, idade e raça; OR aj. soc.: odds ratio ajustado para escolaridade e renda; IC: intervalo de confiança; * $p<0,05$. OR - categoria de referência SA. 
Tabela 3. Prevalência bruta e odds ratios brutos e ajustados para a associação entre IAG e padrão alimentar ( $\mathrm{n}_{\mathrm{SA}}=240$ e $\mathrm{n}_{\mathrm{IAG}}=84$ ). Distrito Federal, 2014 .

\begin{tabular}{lccccccc}
\hline & Feijão & Fruta & Hortaliça & Leite integral & $\begin{array}{c}\text { Refrigerante } \\
\text { normal }\end{array}$ & $\begin{array}{c}\text { Gordura da carne } \\
\text { vermelha }\end{array}$ & Pele frango \\
\hline Prev. (\%) IAG & 52,40 & 2,40 & 13,10 & 54,80 & 47,60 & 39,30 & 35,70 \\
Prev. (\%) SA & 70,00 & 11,70 & 25,40 & 58,30 & 50,00 & 28,80 \\
OR bruto (95\% IC) & $0,47(0,28-0,79)^{*}$ & $0,19(0,04-0,79)^{*}$ & $0,44(0,22-0,89)^{*}$ & $0,87(0,52-1,43)$ & $0,91(0,55-1,50)$ & $1,60(0,95-2,70)$ & $2,11(1,23-3,64)^{*}$ \\
OR aj. bio. (95\% IC) & $0,47(0,28-0,81)^{*}$ & $0,18(0,04-0,77)^{*}$ & $0,39(0,19-0,79)^{*}$ & $0,89(0,53-1,49)$ & $0,95(0,56-1,62)$ & $1,71(0,99-2,94)$ & $2,17(1,23-3,81)^{*}$ \\
OR aj. soc. (95\% IC) & $0,41(0,23-0,73)^{*}$ & $0,19(0,04-0,90)^{*}$ & $0,43(0,20-0,93)^{*}$ & $0,56(0,31-1,01)$ & $0,90(0,51-1,59)$ & $1,83(1,01-3,31)^{*}$ & $1,89(1,02-3,50)^{*}$
\end{tabular}

OR aj. bio.: odds ratio ajustado para sexo, idade e raça; OR aj. soc.: odds ratio ajustado para escolaridade e renda; IC: intervalo de confiança; *: $p<0,05$. OR - categoria de referência SA. 
Tabela 4. Prevalência bruta e odds ratios brutos e ajustados para a associação entre IAG e estado nutricional, atividade física e consumo de bebida alcoólica $\left(n_{S A}=240\right.$ e $\left.n_{1 A G}=84\right)$. Distrito Federal, 2014.

\begin{tabular}{lcccc}
\hline & Sobrepeso & Obesidade & Atividade física & $\begin{array}{c}\text { Consumo abusivo de bebida } \\
\text { alcoólica }\end{array}$ \\
\hline Prev. (\%) IAG & 29,80 & 22,60 & 19,00 & 20,20 \\
Prev. (\%) SA & 35,80 & 11,70 & 34,00 & 27,10 \\
OR bruto (95\% IC) & $0,76(0,44-1,30)$ & $2,21(1,16-4,22)^{*}$ & $0,45(0,24-0,82)^{*}$ & $0,68(0,37-1,25)$ \\
OR aj. bio. (95\% IC) & $0,64(0,37-1,13)$ & $1,86(0,95-3,63)$ & $0,47(0,25-0,87)^{\star}$ & $0,78(0,42-1,47)$ \\
OR aj. soc. (95\% IC) & $0,76(0,44-1,30)$ & $1,71(0,79-3,70)$ & $0,73(0,37-1,44)$ & $0,84(0,44-1,64)$ \\
\hline OR aj. bio.: odds ratio ajustado para sexo, idade e raça; OR aj. soc.: odds ratio ajustado para escolaridade e renda; IC: intervalo de confiança; *: $p<0,05$.
\end{tabular}


Referências

1. Brasil. Lei Orgânica de Segurança Alimentar e Nutricional - LOSAN; Lei no 11.346, de 15 de setembro de 2006.

2. Brasil. Instituto Brasileiro de Geografia e Estatística; Ministério do Desenvolvimento Social e Combate à Fome; Ministério do Planejamento, Orçamento e Gestão. Pesquisa Nacional por Amostra de Domicílio: segurança alimentar 2013. Rio de Janeiro: IBGE; 2014.

3. Seligman HK, Laraia BA, Kushel MB. Food Insecurity Is Associated with Chronic Disease among Low-Income NHANES. J Nutr.2010; 140:304-10.

4. Coleman-Jensen A, Nord M, Andrews M, Carlson S. Household Food Security in the United States in 2010. USDA, Economic Research Service. Washington: USDA; 2011.

5. Cheng S, Kamano J, Kirui NK, Manuthu E, Buckwalter V, Ouma K, Pastakia SD et al. Prevalence of food insecurity in patients with diabetes in western Kenya. Diabet Med. 2013; 30: 215-22.

6. Ramsey R, Giskes K, Turrell G, Gallegos D. Food insecurity among adults residing in disadvantaged urban areas: potential health and dietary consequences. Public Health Nutrition. 2011;15(2):227-37.

7. WHO. World Health Organization. Global status report on non communicable diseases 2010.Geneva: World Health Organization; 2011.

8. Langley-Evans SC, McMullen S. Developmental origins of adult disease. Med Princ Pract. 2010; 19(2):87-98.

9. Laraia BA. Food Insecurity and Chronic Disease. Adv Nutr. 2013; 4:203-12. 
10. Brasil. Ministério da Saúde. Secretaria de atenção à saúde. Departamento de atenção Básica. Guia alimentar para a população brasileira. Brasília: Ministério da Saúde, 2014.

11. Brasil. Ministério da Saúde. Secretaria de Vigilância em Saúde. Vigitel Brasil 2013: vigilância de fatores de risco e proteção para doenças crônicas por inquérito telefônico. Brasília: Ministério da Saúde, 2014.

12. Souza AM, Bezerra LN, Cunha DB, Sichieri R. Avaliação dos marcadores de consumo alimentar do VIGITEL (2007-2009). Rev Bras Epidemiol. 2011; 14(1) Supl.: 44-52.

13. Brasil. Ministério da Saúde. Secretaria de Vigilância em Saúde. CoordenaçãoGeral de Desenvolvimento da Epidemiologia em Serviços. O enfrentamento das doenças crônicas não transmissíveis: um desafio para a sociedade brasileira. Epidemiol. Serv. Saúde 2011; 20(4): 421-24.

14. Malta DC, Júnior JBS. O Plano de Ações Estratégicas para o Enfrentamento das Doenças Crônicas Não Transmissíveis no Brasil e a definição das metas globais para o enfrentamento dessas doenças até 2025: uma revisão. Epidemiol. Serv. Saúde 2013; 22(1):151-64.

15. Horton R, James A, Das P, Kleinert S, Summerskill W, Davies J, et al., editors. The Lancet: Saúde no Brasil. 2011 Mai: 1-102.

16. Schmidt MI, Duncan BB, Silva GA, Menezes AM, Monteiro CA, Barreto SM, et al. Doenças crônicas não transmissíveis no Brasil: carga e desafios atuais. The Lancet. 2011; 61-73.

17. Franklin B, Jones A, Love D, Puckett S, Macklin J, White-Means S. Exploring mediators of food insecurity and obesity: a review of recent literature. J Community Health. 2012; 37(1):253-64. 
18. Gowda C, Hadley C, Aiello AE. The Association Between Food Insecurity and Inflammation in the US Adult Population. Am J Public Health. 2012; 102(8): 1579-86.

19. Egeland GM, Johnson-Down L, Cao ZR, Sheikh N, Weiler H. Food Insecurity and Nutrition Transition Combine to Affect Nutrient Intakes in Canadian Arctic Communities. J Nutr.2011; 141:1746-53.

20. Bawadi HA, Ammari F, Abu-Jamous D, Khader YS, Bataineh S, Tayyeme RF. Food insecurity is related to glycemic control deterioration in patients with type 2 diabetes. Clinical Nutrition.2012; 31:250-4.

21. Velásquez-Melendez G, Schlüssel MM, Brito AS, Silva AAM, Lopes-Filho JD, Kac G. Mild but Not Light or Severe Food Insecurity Is Associated with Obesity among Brazilian Women. J Nutr. 2011;141: 898-902.

22. Kac G, Schlüssel MM, Pérez-Escamilla R, Velásquez-Melendez G, Silva AAM. Household Food Insecurity Is Not Associated with BMI for Age or Weight for Height among Brazilian Children Aged 0-60 Months. PLoS ONE. 2012; 7(9):(e45747)1-7.

23. Kac G, Velásquez-Melendez G, Schlüssel MM, Segall-Corrêa AM, Silva AAM, Pérez-Escamilla R. Severe food insecurity is associated with obesity among Brazilian adolescent females. Public Health Nutrition. 2012; 15(10):1854-60.

24. Schlüssel MM, Silva AAM, Pérez-Escamilla R, Kac G. Household food insecurity and excess weight/obesity among Brazilian women and children: a life-course approach. Cad Saúde Pública. 2013; 29(2):219-26.

25. Santos LMP. Obesity, poverty, and food insecurity in Brazilian males and females. Cad Saúde Pública. 2013; 29(2):219-41.

26. Banco Mundial. Unidade de Gerenciamento do Brasil. Unidade de Gestão do Setor de Desenvolvimento Humano. Relatório No. 32576-BR - Enfrentando o Desafio das Doenças Não Transmissíveis no Brasil. Caribe: Banco Mundial; 2005. 
27. Sartori AGO. Consumo alimentar de beneficiários do Programa Bolsa Família [dissertação]. Piracicaba (SP): Universidade de São Paulo; 2013.

28. Cotta RMM, Machado JC. Programa Bolsa Família e segurança alimentar e nutricional no Brasil: revisão crítica da literatura. Rev. panam. salud pública. 2013; 33(1): 54-60.

29. Cabral CS, Lopes AG, Lopes JM, Vianna RPT. Segurança alimentar, renda e Programa Bolsa Família: estudo de coorte em municípios do interior da Paraíba, Brasil, 2005-2011. Cad Saúde Pública. 2014; 30(2):393-402.

30. de Bem Lignani J, Sichieri R, Burlandy L, Salles-Costa R. Changes in food consumption among the Programa Bolsa Família participant families in Brazil. Public Health Nutr. 2011; 14(5):785-92.

31. Cabral MJ, Vieira KA, Sawaya AL, Florêncio TMMT. Perfil socioeconômico, nutricional e de ingestão alimentar de beneficiários do Programa Bolsa Família. Estud. av.2013; 27(78): 71-87.

32. Seligman HK, Schillinger D. Hunger and Socioeconomic Disparities in Chronic Disease. N Engl J Med. 2010; 363(1): 6-9.

33. Chilton M, Booth $\mathrm{S}$. Hunger of the body and hunger of the mind: African american women's perceptions of food insecurity, health and violence. J NutrEducBehav.2007; 39: 116-25.

34. Gowda C, Hadley C, Aiello AE. The Association Between Food Insecurity and Inflammation in the US Adult Population. Am J Public Health. 2012; 102(8):1579-86.

35. Shankar A, Li J, Nieto FJ, Klein BE, Klein R. Association between C-reactive protein level and peripheral arterial disease among US adults without cardiovascular disease, diabetes, or hypertension. Am Heart J. 2007; 154(3): 495 - 501. 
36. Vepsalainen T, Soinio M, Marniemi J, et al. Physical activity, high-sensitivity Creactive protein, and total and cardiovascular disease mortality in type 2 diabetes. Diabetes Care. 2011; 34(7):1492 - 96.

37. Robaina KA, Martin KS.Food Insecurity, Poor Diet Quality, and Obesity among Food Pantry Participants in Hartford, CT. J. nutr. educ. behav. 2013; 45: 159-64.

38. Mohamadpour M, Sharif ZM, Keysami MA. Food insecurity, health and nutritional status among sample of palm-plantation households in Malaysia. J Health Popul Nutr. 2012; 30(3): 291-302.

39. López ABS, Seligman HK. Clinical management of food-insecure individuals with diabetes. Diabetes Spectr. 2012; 25(1): 14-8.

40. Green-La Pierre RJ, Williams PL, Glanville NT, Norris D, Hunter HC, Watt CG. Learning from "knocks in life": food insecurity among low-income lone senior women. J Aging Res. 2012; 2012: 1-11.

41. Mark S, Lambert M, O'Loughlin J, Gray-Donald K. Household income, food insecurity and nutrition in Canadian Youth. Can J Public Health. 2012; 103(2): 94-99.

42. Foley W, Ward P, Carter P, Coveney J, Tsourtos G, Taylor A. An ecological analysis of factors associated with food insecurity in South Australia, 2002-7. Public Health Nutr.2009; 13(2): 215-21.

43. Deus ACS, Santos ALB, Gubert MB. Associação entre ocorrência e fatores de risco de doenças crônicas não transmissíveis e insegurança alimentar pregressa em adultos do Distrito Federal. Demetra 2014; 9(4); 893-901.

44. Ferreira-Batista N, Cacciamali MC. Migração familiar, trabalho infantil e ciclo intergeracional da pobreza no estado de São Paulo. Nova econ. 2012; 22(3): 515-54. 


\section{CONCLUSÕES}

Tendo em vista que grupos menos privilegiados têm grande participação nas taxas de DCNT e IAG, entender a associação entre essas taxas é de fundamental importância para o planejamento de políticas públicas mais eficientes para manutenção das condições de saúde e segurança alimentar desses indivíduos.

A revisão da literatura permitiu elucidar a relação de influência da IA na causa e no controle das DCNT, que ocorre devido adaptações dietéticas inadequadas desencadeadas pela IA, com estratégias compensatórias durante a adequação alimentar e a escassez de alimentos, levando ao quadro de obesidade, hipertensão e diabetes. Este quadro prejudica a capacidade de autogestão da doença, além de gerar demandas conflitantes, que por sua vez aumentam a vulnerabilidade econômica, mental, física e social, fechando o ciclo de relação entre a IA e a DCNT.

Este estudo aponta para tendência de associação positiva da IAG com DCNT (DCV, diabetes e câncer), consumo de carnes com excesso de gordura e obesidade. Sugerindo que a IAG atuaria como fator preditivo de DCNT e ocorrência de seus fatores de risco. Também foi observada tendência de associação negativa da IAG com prática de atividade física, consumo de feijão, frutas e hortaliças, sugerindo que a IAG dificulta a adoção de comportamentos protetivos contra DCNT.

Os achados desta pesquisa demonstram que para combater as DCNT faz-se necessário empenho em traçar estratégias para redução da situação de IAG, por meio do aumento da utilização de programas sociais e da inclusão da educação alimentar e nutricional em todos os programas governamentais que trabalhem para redução da fome e pobreza. 


\section{REFERÊNCIAS}

1. Brasil. Lei Orgânica de Segurança Alimentar e Nutricional - LOSAN; Lei no 11.346, de 15 de setembro de 2006.

2. Pérez-Escamilla R, Segall-Corrêa AM. Food insecurity measurement and indicators. Rev. Nutr. 2008; 21(suplemento): 15s-26s.

3. Brasil. Instituto Brasileiro de Geografia e Estatística; Ministério do Desenvolvimento Social e Combate à Fome; Ministério do Planejamento, Orçamento e Gestão. Pesquisa Nacional por Amostra de Domicílio: segurança alimentar 2013. Rio de Janeiro: IBGE; 2014.

4. FAO. Food and Agriculture Organization of the United Nations. The State of Food Insecurity in the World: Strengthening the enabling environment for food security and nutrition. Rome: FAO, IFAD and WFP; 2014.

5. IPEA. Instituto de Pesquisa Econômica Aplicada e Secretaria de Planejamento e Investimentos Estratégicos (coordenação). Grupo Técnico para o acompanhamento dos ODM (supervisão). Objetivos de Desenvolvimento do Milênio: Relatório Nacional de Acompanhamento. Brasília: Ipea; 2014.

6. Ramsey R, Giskes K, Turrell G, Gallegos D. Food insecurity among adults residing in disadvantaged urban areas: potential health and dietary consequences. Public Health Nutr. 2011; 15(2): 227-37.

7. Seligman HK, Schillinger D. Hunger and Socioeconomic Disparities in Chronic Disease. N Engl J Med. 2010; 363(1): 6-9.

8. Chilton M, Booth S. Hunger of the body and hunger of the mind: African american women's perceptions of food insecurity, health and violence. J NutrEducBehav.2007; 39: 116-25. 
9. Tanumihardjo SA, Anderson C, Kaufer-Horwitz M, Bode L, Emenaker NJ, Haqq AM, et al. Poverty, obesity, and malnutrition: an international perspective recognizing the paradox. J Am Diet Assoc. 2007; 107: 1966-72.

10. Laraia BA. Food Insecurity and Chronic Disease. Adv Nutr.2013; 4:203-12.

11. WHO. Preventing chronic diseases: a vital investment. Geneva: World Health Organization, 2005.

12. Horton R, James A, Das P, Kleinert S, Summerskill W, Davies J et al., editors. The Lancet: Saúde no Brasil. 2011 Mai: 1-102.

13. Bawadi HA, Ammari F, Abu-Jamous D, Khader YS, Bataineh S, Tayyeme RF. Food insecurity is related to glycemic control deterioration in patients with type 2 diabetes. Clinical Nutrition.2012; 31:250-4.

14. Gowda C, Hadley C, Aiello AE. The Association Between Food Insecurity and Inflammation in the US Adult Population. Am J Public Health. 2012; 102(8):1579-86.

15. Egeland GM, Johnson-Down L, Cao ZR, Sheikh N, Weiler H. Food Insecurity and Nutrition Transition Combine to Affect Nutrient Intakes in Canadian Arctic Communities. J Nutr.2011; 141:1746-53.

16. Seligman HK, Laraia BA, Kushel MB. Food Insecurity Is Associated with Chronic Disease among Low-Income NHANES Participants. J Nutr.2010; 140: 304-10.

17. WHO. World Health Organization. Global status report on non communicable diseases 2010. Geneva: World Health Organization; 2011.

18. Schlüssel MM, Silva AAM, Pérez-Escamilla R, Kac G. Household food insecurity and excess weight/obesity among Brazilian women and children: a life-course approach. Cad Saúde Pública. 2013; 29(2):219-26. 
19. Santos LMP. Obesity, poverty, and food insecurity in Brazilian males and females. Cad Saúde Pública. 2013; 29(2):219-41.

20. Kac G, Schlüssel MM, Pérez-Escamilla R, Velásquez-Melendez G, Silva AAM. Household Food Insecurity Is Not Associated with BMI for Age or Weight for Height among Brazilian Children Aged 0-60 Months. PLoS ONE. 2012; 7(9):(e45747)1-7.

21. Kac G, Velásquez-Melendez G, Schlüssel MM, Segall-Corrêa AM, Silva AAM, Pérez-Escamilla $R$. Severe food insecurity is associated with obesity among Brazilian adolescent females. Public Health Nutrition.2012; 15(10):1854-60.

22. Velásquez-Melendez G, Schlüssel MM, Brito AS, Silva AAM, Lopes-Filho JD, Kac G. Mild but Not Light or Severe Food Insecurity Is Associated with Obesity among Brazilian Women. J Nutr. 2011;141: 898-902.

23. Brasil. Instituto Brasileiro de Geografia e Estatística; Ministério do Desenvolvimento Social e Combate à Fome; Ministério do Planejamento, Orçamento e Gestão. Pesquisa Nacional por Amostra de Domicílio: segurança alimentar 2004/2009. Rio de Janeiro: IBGE; 2010.

24. Brasil. Ministério da Saúde. Secretaria de Vigilância em Saúde. Vigitel Brasil 2011: Vigilância de Fatores de Risco e Proteção para Doenças Crônicas por Inquérito Telefônico. Brasília: Ministério da Saúde, 2012.

25. Souza AM, Bezerra LN, Cunha DB, Sichieri R. Avaliação dos marcadores de consumo alimentar do VIGITEL (2007-2009). Rev Bras Epidemiol. 2011; 14(1) Supl.: 44-52. 


\section{APÊNDICES}


APÊNDICE A - QUESTIONÁRIO 


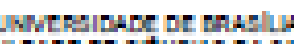

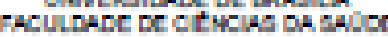

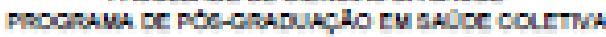

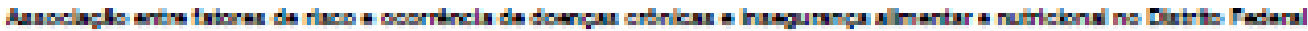

\section{TRASEM}

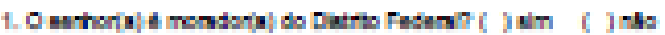

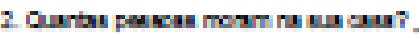
Dunbu of ate mar

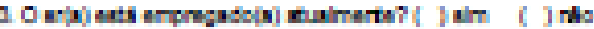

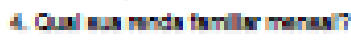
Rentidombllor par enpla:

................

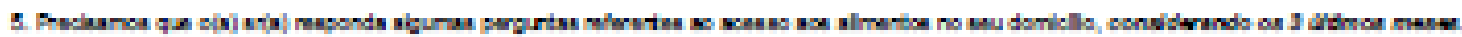

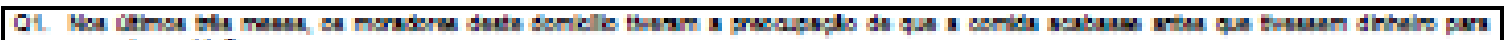

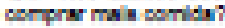

$11 \mathrm{in}$

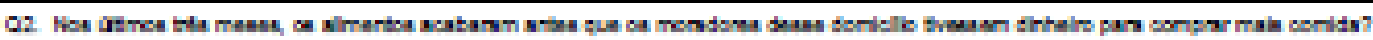
1 1 in
in He
[ ] Кำ

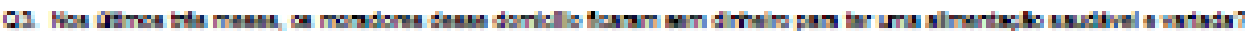
I IIT
inis.
I I KEMP

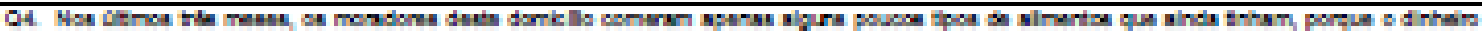
cabor

$$
\text { HEH GHAS TIREST }
$$

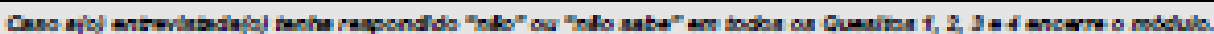

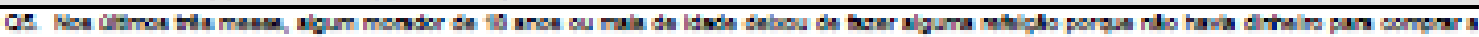
corita?

\begin{tabular}{|c|c|c|}
\hline MIn & I HNS & I I HESA \\
\hline
\end{tabular}

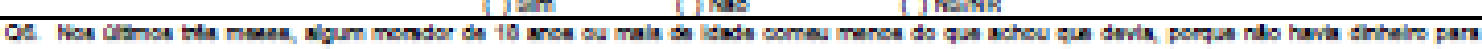
aspror anits?

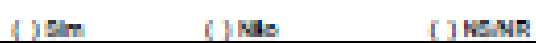

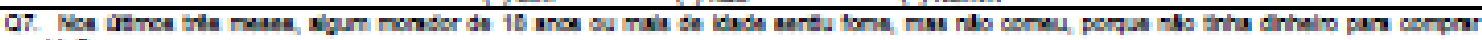

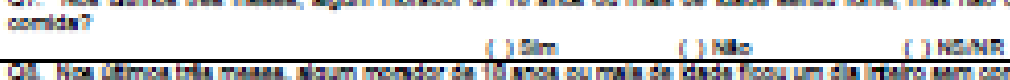

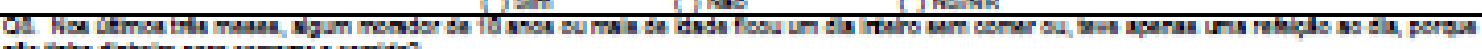

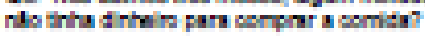

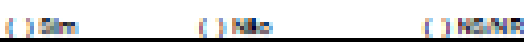

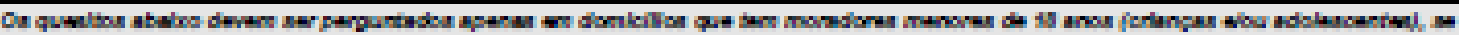

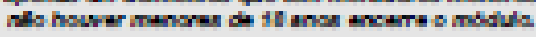

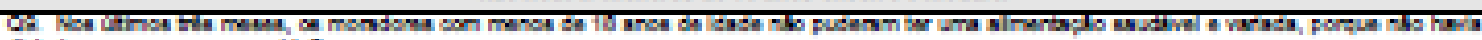

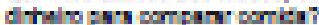

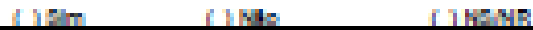

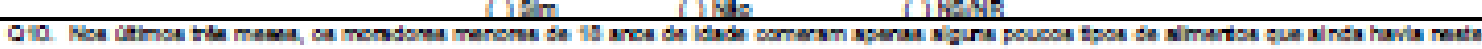

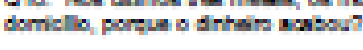

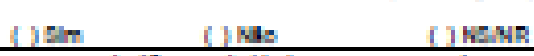

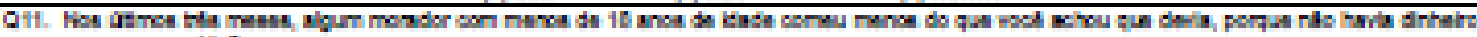

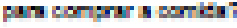

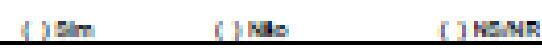

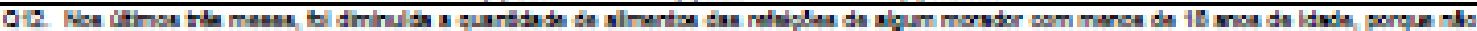

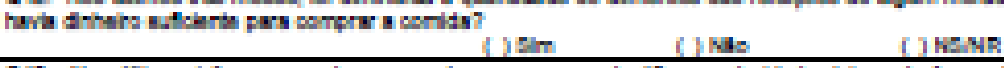

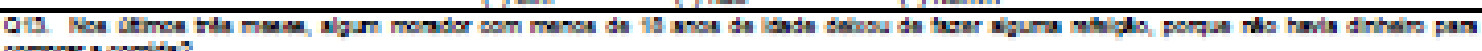

\begin{tabular}{|c|c|c|}
\hline \multirow{2}{*}{ Chuntapila } & \multicolumn{2}{|c|}{ 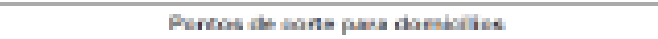 } \\
\hline & 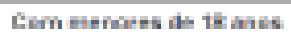 & 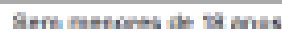 \\
\hline 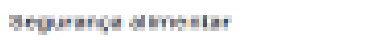 & $\pi$ & $\pi$ \\
\hline 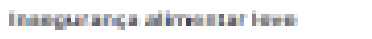 & $i \cdot \bar{L}$ & $1 \cdot 3$ \\
\hline 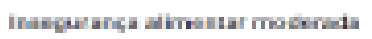 & d. & S. E \\
\hline 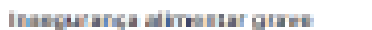 & 1a. 14 & d. \\
\hline
\end{tabular}
anpreming

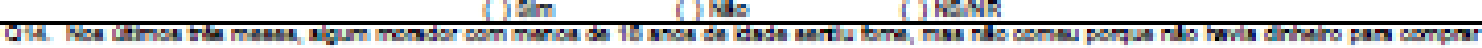
mationith

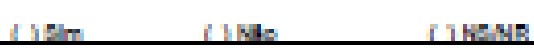

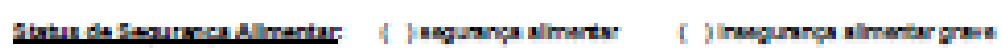

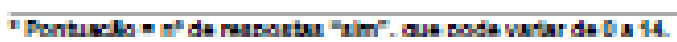

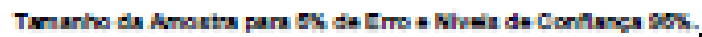

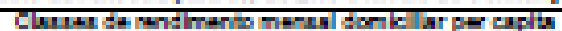

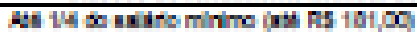

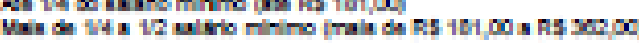

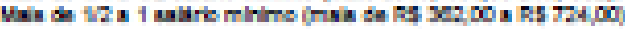

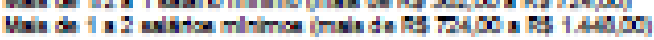

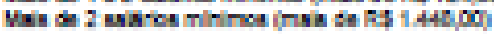

Gen mindrents

Total

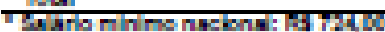

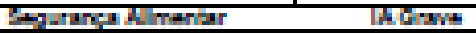

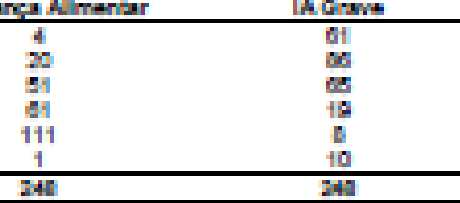




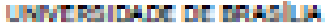

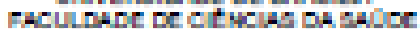

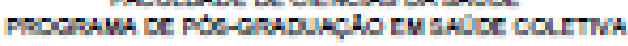

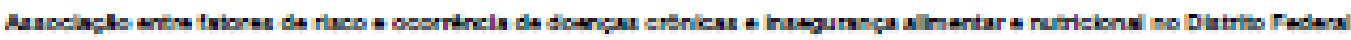

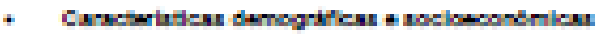

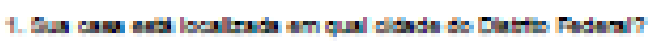

\begin{tabular}{|c|c|c|c|c|}
\hline 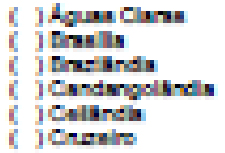 & 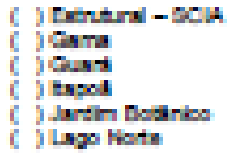 & 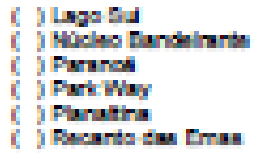 & 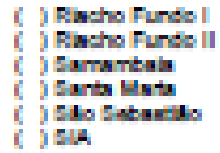 & 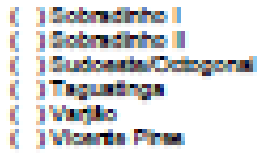 \\
\hline
\end{tabular}

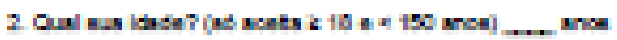

$1 . \operatorname{lng}$

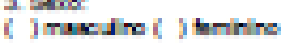

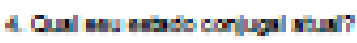

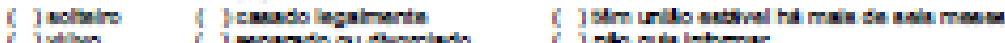

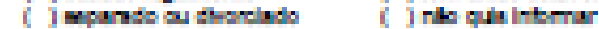

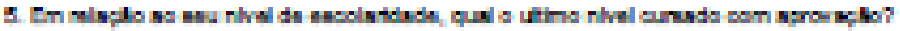

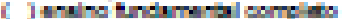

(1)

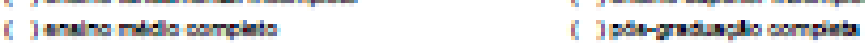

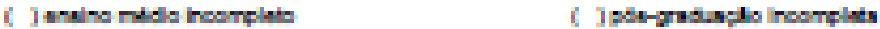

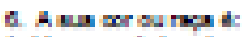

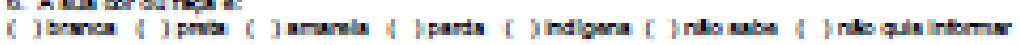

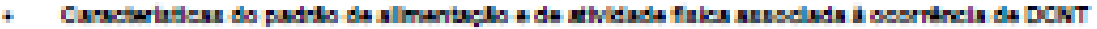

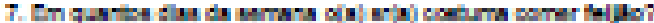

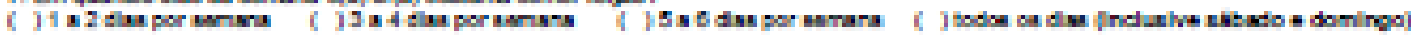

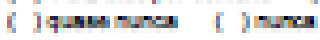

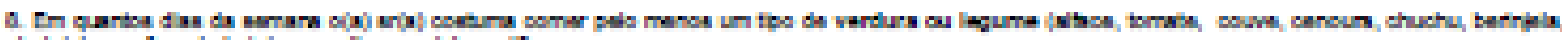

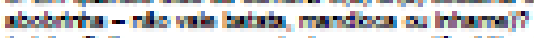

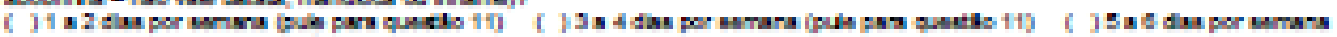

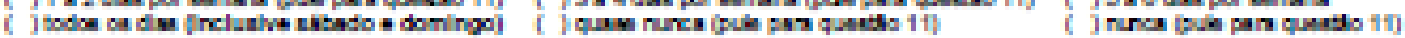

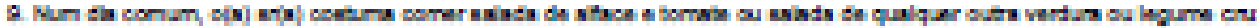

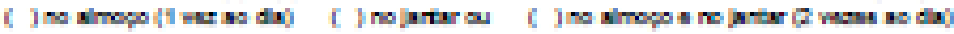

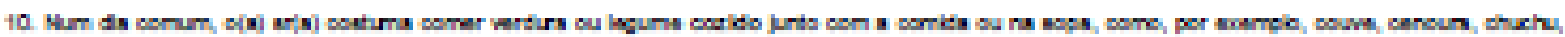

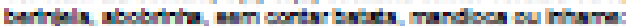

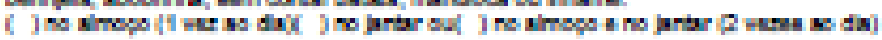

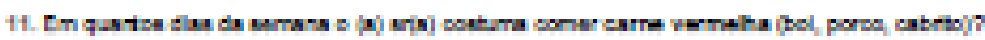

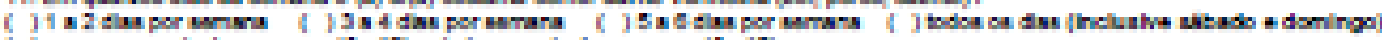

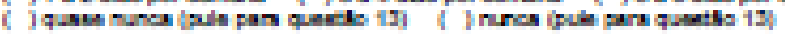

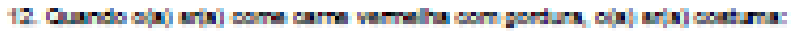

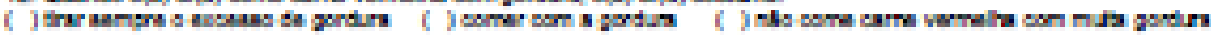

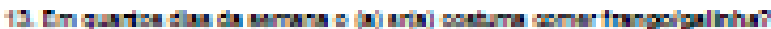

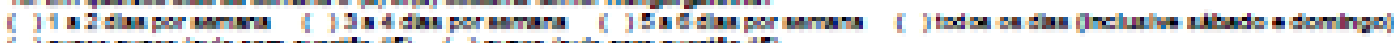

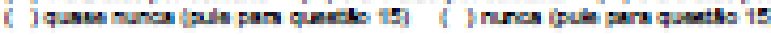

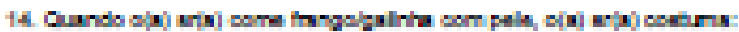

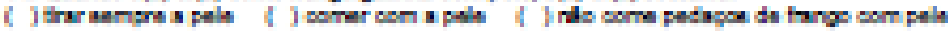

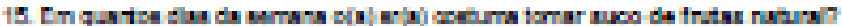

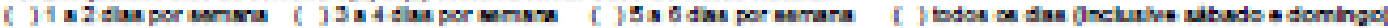

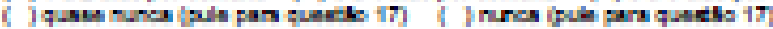

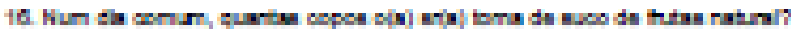

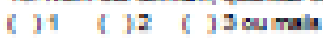

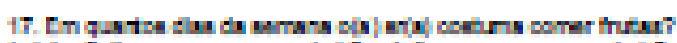

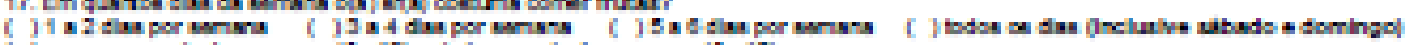

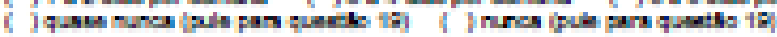

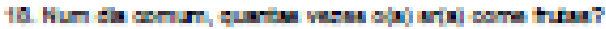

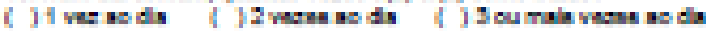

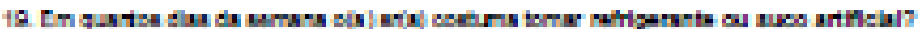

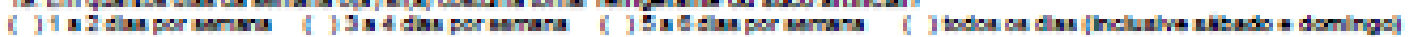

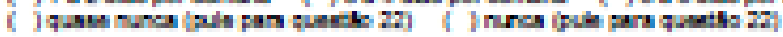

30. auston

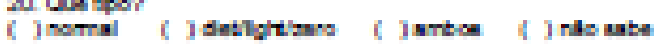

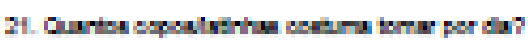

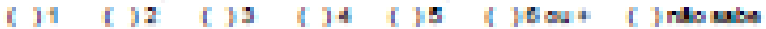




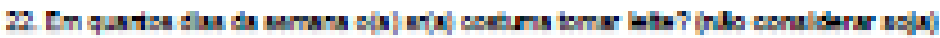

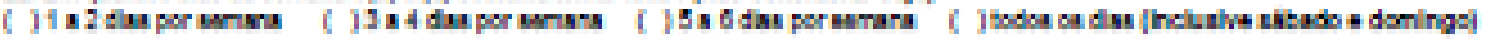

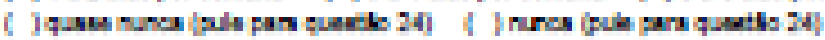

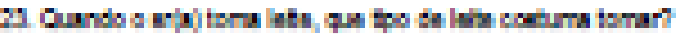

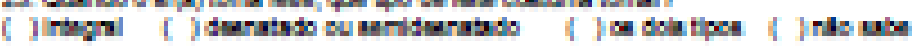

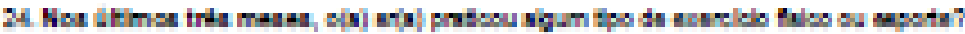

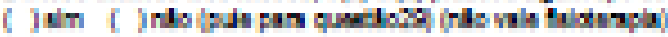

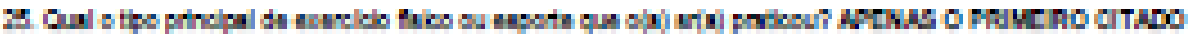

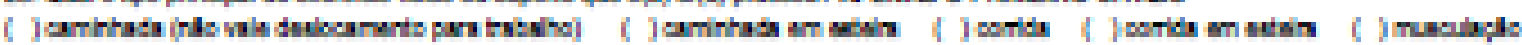

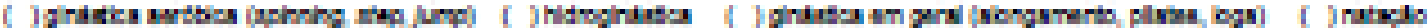

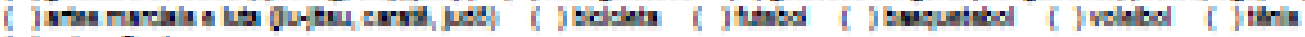

1 istran En:

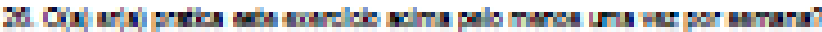

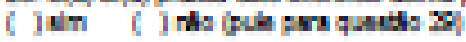

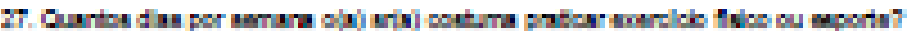

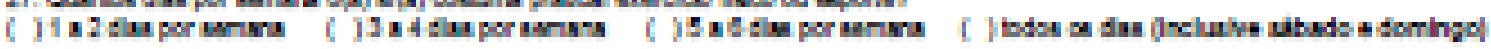

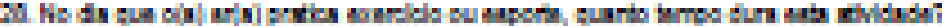

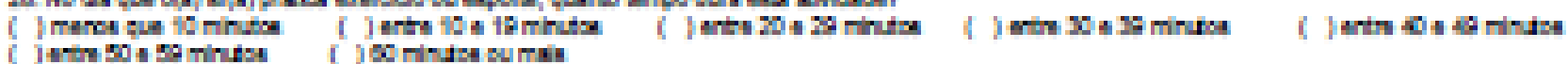

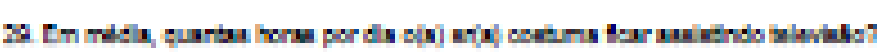

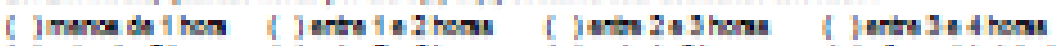

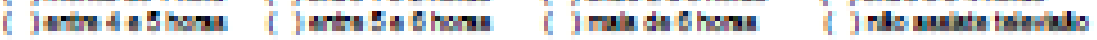

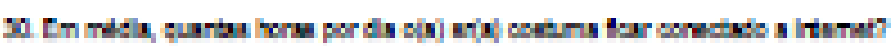

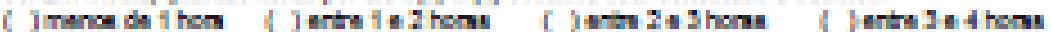

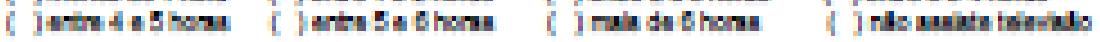

Pane enturs raferides

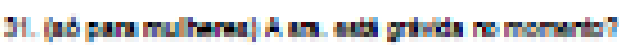

intm in in inuth

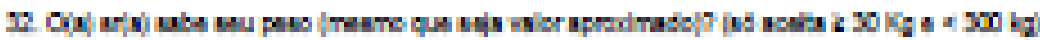

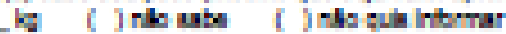

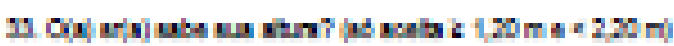

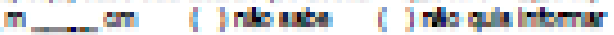

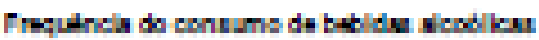

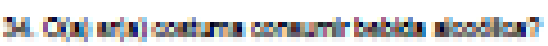

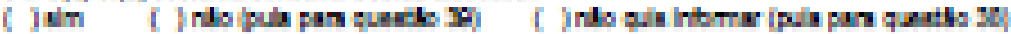

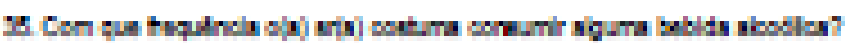

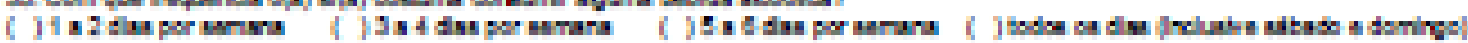

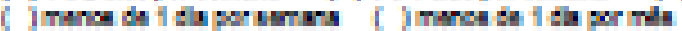

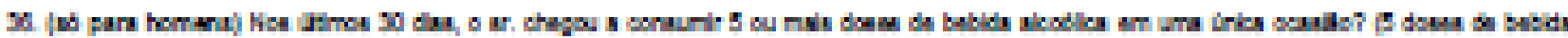

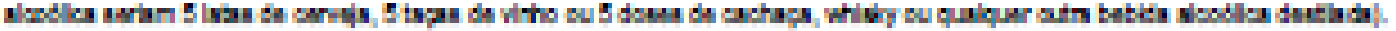

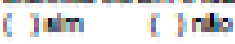

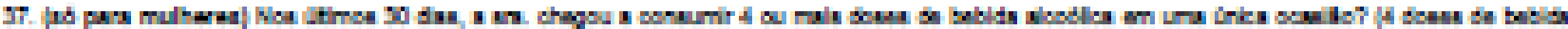

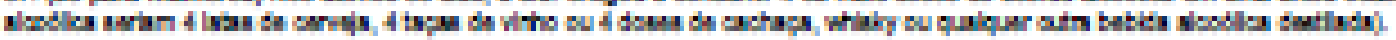

int inl.

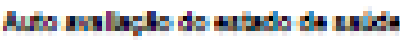

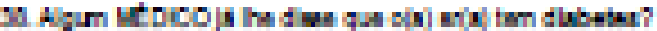

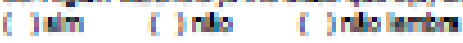

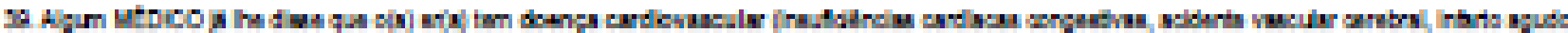

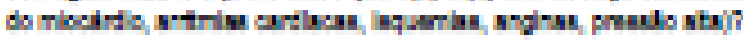

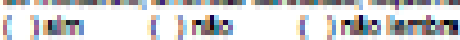

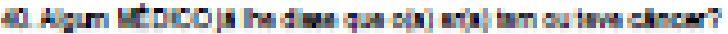

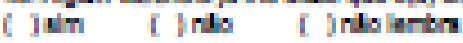


APÊNDICE B - TERMO DE CONSENTIMENTO LIVRE E ESCLARECIDO 


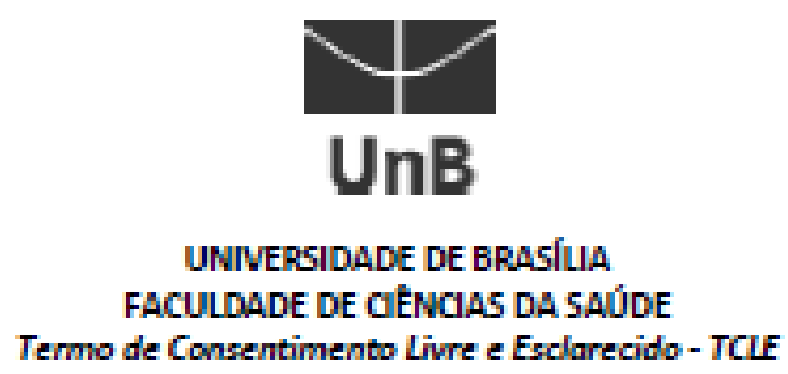

O (a] Senhor(a) etá sendo conidado(a) a participar do projeto: Associsçâio entre fstores de risco e acorrếncia de doenças aỏnicas e insegurança slimentar e nutricianal no Distrito Federal.

O objetivo desta pesquia É: Analisar a associaço entre fatores de risco e cocorréncia de doenças crốnicas e insegurança a limentar e nutricional no Distrito Federal.

O[a) senhor[a] receberá todos os exdarecimentos necessários antes e no decorrer da pescuisa e the asceguramos que seu nome nổo aparecerá sendo mantido o mais rigoroco sigilo atrovés da omizsto total de quaisquer informaçóe que pemilam identifica-lo(a).

A sua participaçio seŕ atróx de uma entrevista com um tempo extimado para sua realizaçio de aproximadamente 10 minutos. Informamos que o(a) Senhor(a) pode se recusar a responder qualquer quetho que the traga conatrangimento, podendo desistir de participar da pescuisa em qualquer momento sem nenhum prejuizo para o(a) senhor(a). Sua participaçố é voluntária, isto é, näo há pagamento por zua colaboraça

Os resultados da pesquiza serifo divulgados na Instituiçio Universidade de Brailín,

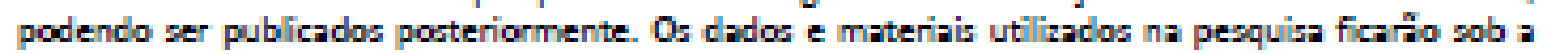
guarda do pesquicador por um período de no mínimo cinco ance, apó isso serho destruídos ou mantidos na instituiç̧̌̃o.

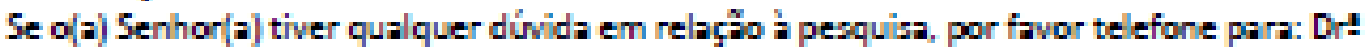
Muriel Bauermann Gubert, na Universidade de Erasilia telefone: 61-3307.2543, no horário 9h Ba 11h.

Este projeto foi Aprovado pelo Comitë de ttica em Pesquisa da Faculdade de Ciéncias da Saúde da Universidade de Brasilia. As dúvidas com relaçto b ascinatura do TCLE ou os direitos do sujeito da pesquisa podem ser abtidos através do telefone [61) 3107-1947 ou do email ceptepunbibr.

Este documento foi elaborado em duas vias, uma ficarí com o pesquizador respontivel e a outra com o sujeito da pesquizer.

Nome/asinatura

Pezqüàdor Responstivel

Nome e ascinatura

Brasilia. de de 
ANEXOS 
ANEXO A - PARECER CONSUBSTANCIADO DO CÔMITE DE ÉTICA EM PESQUISA 


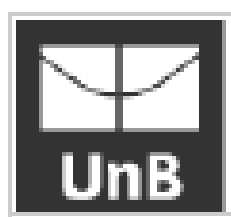

\section{FACULDADE DE CIÊNCIAS DA SAÚDE DA UNIVERSIDADE DE BRASILIA - CEPIFS-UNB}

\section{PARECER CONSUBSTANCIADO DO CEP}

\section{DADOS DO PROJETO DE PESQUISA}

Titulo da Pasqulag: Asscolacto entre fatores de rlsco e coomencla de doenças crólcas e Insegurança almentair e nutriclonal no Distrito Federal

Pegqulgador: MURIEL BAUERWANN GUGERT

Area Tenatica:

Veras: 2

CAAE: 183408138.0000.0030

Inattukgao Proponente: FACULDADE DE SALDE - FS

Patrocinador Princlpal: Financlanento Proprlo

\section{DADOS DO PAFECER}

Nümero do Parecer. 302.831

Data da Relatorla: 28062013

Apresentsgo do Projeto:

A Insegurança allmentar (IA) pode ser entendida como a Incapacldade ou lncerteza da aquls/plo de almentos nutriclonaimente adequados e culturalmente apropriados e seguros. Os efeltos da lA podem resultar em encargos significatwos para a saude püblica. Ela esta

relaclonada a diminulço do consumo de alguns grupos de almentos, bem como da varledade e do tamanho das porçbes dos almentos,desencadeando Inadequaço da Ingestäo de nutrlentes, com consequente impacto na redugto do estado geral de caude e aumento do numero de viltas ao medco ou hospital. Fecentenente, tem havdo especulaches de que a lA atual tamben pode apresentar relago de cauka com doenças cronlcas, princlpal forte da carga de doençs no Brall, ten se tomado a prindpal prondade na area da siude.

\section{Objetivo da Peaqulsa:}

ogjetvo Geral:

Analkar a assoclapto entre fatores de row e coomenca de doenças crónlcas e Insegurança al mentar e nutridonal no Distrito Federal.

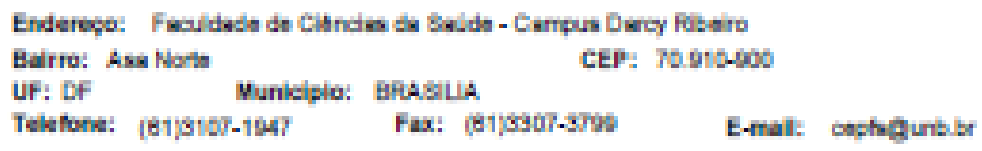




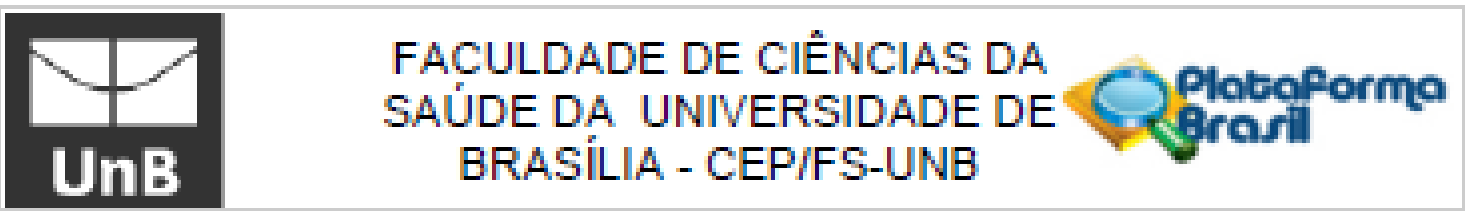

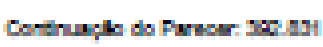

Oojettuos especiloos:

-Descrever a coortenda de doenças counlcas na populagto investlgada com inseguranga almentar,

-Verifcar os fatores de risco pera doenças cronlcas presentes na populato com IA:

- Entender a asoclacto entre as variavels doenças cronlcas e IA

Avallagto dos Rlacos 6 Beneticlos:

os posslvels benefliclos apresentam-se com malor magnitude em relaço acs riscos posehels para os sujeltos da pesqusa. Esta presentes antecedentes dentifos que jusitilquem a pesqusa. Os objethos da pesqulsa estäo definidos.

\section{Comentarlos e Consideraçes sobre a Pesqulsa:}

Trata-ce de um estudo transversal por telefone Junto a base de dados de telefones domlallares do Distrito Federal, seguindo a metodologla empregada em 2011 no Vgitel Villancla de Fatores de Rlsco e Proteço para Doenças Cronlcas por Inquerto Telétonico (Erasl, 2012). A amostra sera probabllstica de adultos residentes em domicillos servidos por, pelo mencs, uma IInha telefonica fixa. Os criterios de linclusto e exclusto estâo devidamente estabelecidos. Os dados serdo coletados por melo digltal, com uso de computador e entrevista telefonlca. Sera decenvolvdo sotware especialmente para a pesqulsa. 0 questionarlo sera em melo dlglial, con pergurtas fechadas que serdo preenchldas por equipe, devidamente trelnada, de pessos fislos (nivel medlo) contratadas para atividade de apolo as lgaples pelo perlodo de dos meses, sen vinculo empregaticlo.

Ha apresentacto dos princlplos eticos de respelto pela autonomla das pessoas, bem como da obrigacto etca de aumentar ao maximo os beneficlos e reduzir ao minimo os danos. Por se tratar de entrevlata por teletone, o consentimento live e esclarecido serd substibuldo pelo consentimento vertal, obtido por ocasla dos contatos teleforicos com os entrevistados.

Conaldergoes sobre os Termos de apresentapao obrilgatorla:

Os termos de apresentacto obilgatöla estalo conetos.

Recomendaçoes:

Solctamos ao pesqusador.

a. Apresentaço do instrumento de coleta de dados -PENDENCIA ATENDIDA

b. Aüualzaç5o do cronograma apresentado - PENDENCIA.ATENDIDA

Concluabes ou Pendenclas e Lista de Inadequacbes:

APRONADO

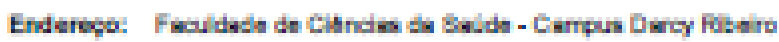

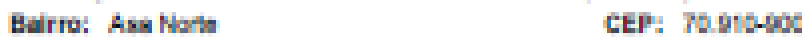

UF: DF Munkigio: BRABLA

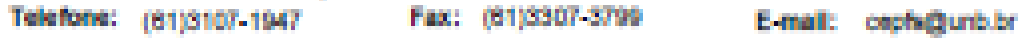




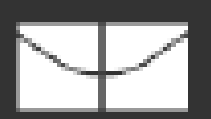

FACULDADE DE CIÊNCIAS DA SAÚDE DA UNIVERSIDADE DE BRASILIA - CEP/FS-UNB

UnB

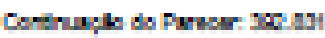

Situsço do Parecer:

Aprovado

Nacesalta Apreclayto da CONEP:

N50

Conaldergoes Fnals a citterlo do CEP:

BRASIIA, 12 de Seternbo de 2013

Asainador por:

Natan Monsores de sa

(Coordenador)

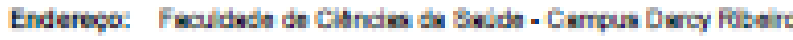

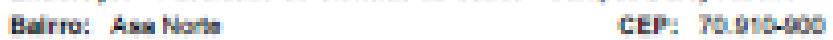

UF: CF Nunklpla: BHAsid

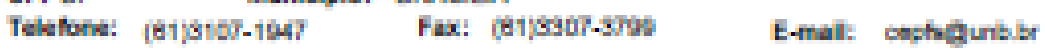

